\title{
Determinants of the perception of sagittal motion
}

\author{
WALTER C. GOGEL and JEROME D. TIETZ \\ University of California, Santa Barbara, California
}

\begin{abstract}
This study examines the change in the perceived distance of an object in three-dimensional space when the object and/or the observer's head is moved along the line of sight (sagittal motion) as a function of the perceived absolute (egocentric) distance of the object and the perceived motion of the head. To analyze the processes involved, two situations, labeled $A$ and $B$, were used in four experiments. In Situation A, the observer was stationary and the perceived motion of the object was measured as the object was moved toward and away from the observer. In Situation B, the same visual information regarding the changing perceived egocentric distance between the observer and object was provided as in Situation A, but part or all of the change in visual egocentric distance was produced by the sagittal motion of the observer's head. A comparison of the perceived motion of the object in the two situations was used to measure the compensation in the perception of the motion of the object as a result of the head motion. Compensation was often clearly incomplete, and errors were often made in the perception of the motion of the stimulus object. A theory is proposed, which identifies the relation between the changes in the perceived egocentric distance of the object and the tandem motion of the object resulting from the perceived motion of the head to be the significant factor in the perception of the sagittal motion of the stimulus object in Situation B.
\end{abstract}

If an object moves sagittally toward or away from a stationary observer, the changing egocentric distance of the object will be perceived, assuming that effective visual cues of object motion are available. The identical visual cues of sagittal motion between the observer and object can also be produced by keeping the object physically stationary and moving the observer toward or away from the object at the same speed and through the same distance as that previously used with the moving object. In order to perceive the object as moving in the former case and as stationary in the latter case, the observer must have proprioceptive or other information regarding his or her own stationariness or motion, respectively. Thus, kinesthetic and proprioceptive information regarding self-motion are thought to enable the observer to determine whether the changing visual cues of distance are due to object motion, to observer motion, or to some combination of both. This taking into account of self-motion when the observer is presented with changes in visual information is sometimes called compensation. Compensation for head motion is considered to occur for frontoparallel as well as for sagittal motions of the head (Wallach, 1985, 1987; Wallach \& Flaherty, 1975; Wallach, Stanton, \& Becker, 1974).

However, the presence of visual cues of changing sagittal distance between the object and observer, together with additional information regarding the observer's own sta-

The preparation of this article was supported by Research Grant MH39457 from the United States National Institute of Mental Health. The authors thank Myron L. Braunstein and three anonymous reviewers for their helpful comments on an earlier version of this manuscript. Correspondence should be addressed to Walter C. Gogel, Department of Psychology, University of California, Santa Barbara, CA 93106. tionariness or motion, does not ensure that the observer will accurately perceive the motion or stationariness of the stimulus. As will be considered, a third factor is also important-that is, errors in the perception of the egocentric distance, or errors in the perception of changes in the egocentric distance, of the stimulus object. A related case of the effect of errors in perceived distance is shown in Figure 1-in this case, an effect on the perception of the lateral motion of a stimulus object as viewed from a laterally moving head. In Figure 1, the open circles and primed notation represent perceived characteristics, and the filled circle and unprimed notation represent physical characteristics. A situation is illustrated in which the head is moved laterally through a perceived, $K^{\prime}$, and physical, $K$, distance (where $K^{\prime}=K$ ) while viewing a point of light (the solid circle) located at a physical distance $D_{\mathrm{m}}$. If the point appears (open circle) at $D_{\mathrm{m}}^{\prime}$ (where $D_{\mathrm{m}}^{\prime}=D_{\mathrm{m}}$ ), the point will appear stationary as the head is moved, assuming that the change in perceived direction $\phi^{\prime}$ is equal to the change in the physical direction $\phi$ of the point. If, however, the perceived distance of the point is greater than its physical distance $\left(D_{\mathrm{f}}^{\prime}>\right.$ $\left.D_{\mathrm{m}}\right)$, the point will appear to move $\left(W_{\mathrm{f}}^{\prime}\right)$ in a direction opposite to the perceived direction of the motion of the head. Or, if the perceived distance of the point is less than its physical distance $\left(D_{\mathbf{n}}^{\prime}<D_{\mathbf{m}}\right)$, the point will appear to move $\left(W_{\mathrm{n}}^{\prime}\right)$ in the same direction as the perceived motion of the head. Thus, an error in the perceived egocentric distance of the stimulus object will result in an illusory perception of the motion of the stimulus object, despite the observer's correct perception of the head motion and correct perception of the changing direction (Gogel, 1990). Also, it should be noted that the phenomena illus- 


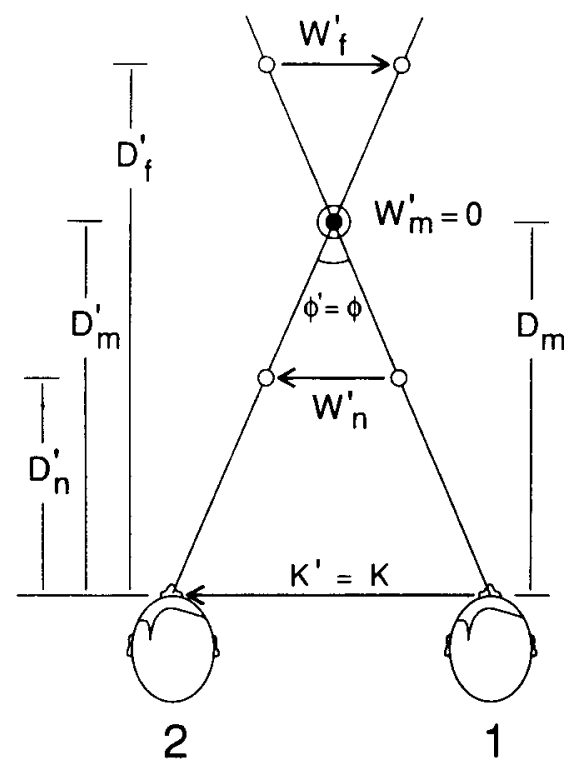

Figure 1. A diagram illustrating a method of measuring perceived distance $\left(D^{\prime}\right)$ by measuring the perceived lateral motion $\left(W^{\prime}\right)$ of the physically stationary stimulus object (the filled circle) located at the physical distance $D_{\mathrm{m}}$ but perceived at $D_{\mathrm{n}}^{\prime}, D_{\mathrm{m}}^{\prime}$, or $D_{\mathrm{f}}^{\prime}$ (the open circles) as the head is moved laterally through the physical distance $K$. At $D_{\mathrm{a}}^{\prime}, W_{\mathrm{a}}^{\prime}$ is in the same direction as the head motion. At $D_{\mathrm{m}}^{\prime}$, $W_{m}^{\prime}$ is zero, and at $D_{t}^{\prime}, W_{\mathrm{f}}^{\prime}$ is in a direction opposite to that of the head motion. $D^{\prime}$ can be obtained from $W^{\prime}$ by using Equation 2, which contains two simplifying assumptions as discussed in the text.

trated in Figure 1 can provide a method of measuring the perceived distances $\left(D_{\mathrm{f}}^{\prime}, D_{\mathrm{m}}^{\prime}\right.$, or $\left.D_{\mathrm{n}}^{\prime}\right)$ of the stimulus object physically stationary at $D_{\mathrm{m}}$. It can be shown from Figure 1 that

$$
D^{\prime}=\left(K^{\prime}-W^{\prime}\right) / 2 \tan \left(\phi^{\prime} / 2\right) .
$$

Equation 1 is expressed entirely in the perceptual terms $D^{\prime}, K^{\prime}, \phi^{\prime}$ and $W^{\prime}$. However, if the experimenter is willing to assume in measuring the perceived distance, $D^{\prime}$, that $K^{\prime}=K$ and $\phi^{\prime}=\phi$, as is illustrated in Figure 1, Equation 1 becomes

$$
D^{\prime}=D\left(K-W^{\prime}\right) / K,
$$

where $D$ is the physical distance of the stimulus object ( $D_{\mathrm{m}}$ in Figure 1) from the observer. The assumptions that $K^{\prime}=K$ and $\phi^{\prime}=\phi$ are convenient, in that they obviate the need to measure $K^{\prime}$ and $\phi^{\prime}$ in Equation 1 in order to compute $D^{\prime}$ from $W^{\prime}$. However, Equation 1 is the more general equation, in that it is expected to hold regardless of the relation between perceived and physical head motion and/or changing direction of the stimulus object. Equation 1, unlike Equation 2, is a phenomenal, not a psychophysical, equation.

Hypothetical illustrations suggesting that errors in the perceived sagittal motion of a physically stationary stimulus can occur from errors in perceived distance, despite the correct perception of the stationariness or sagittal motion of the head, are shown in Figures 2 and 3. Again, the prime notation and open bars indicate perceptual quan- tities. For example, $D_{\mathrm{f}}^{\prime}$ or $D_{\mathrm{n}}^{\prime}$ represents a perceived (egocentric) distance, and $d_{\mathrm{g}}^{\prime}$ denotes a perceived sagittal geographic motion-that is, a perceived motion relative to the stationary environment. The unprimed notation and solid bars represent physical quantities-that is, $D_{\mathrm{f}}$ or $D_{\mathrm{n}}$ represents a physical (egocentric) distance, and $d_{\mathrm{g}}$ denotes a physical geographic motion. A glossary of the major terms used in this study is given in the Appendix.

In Figure 2, drawing A illustrates a situation in which the observer is physically stationary and a stimulus object moves at a constant speed toward the observer between the physical distances $D_{\mathrm{f}}$ and $D_{\mathrm{n}}$. If the perceived starting (initial) distance of the object from the observer is accurate, if the observer perceives himself or herself as stationary, and if effective cues of the initial and changing distance, $D_{\mathrm{f}}-D_{\mathrm{n}}$, of the object are present, the object's motion will be perceived correctly. Consider, how-
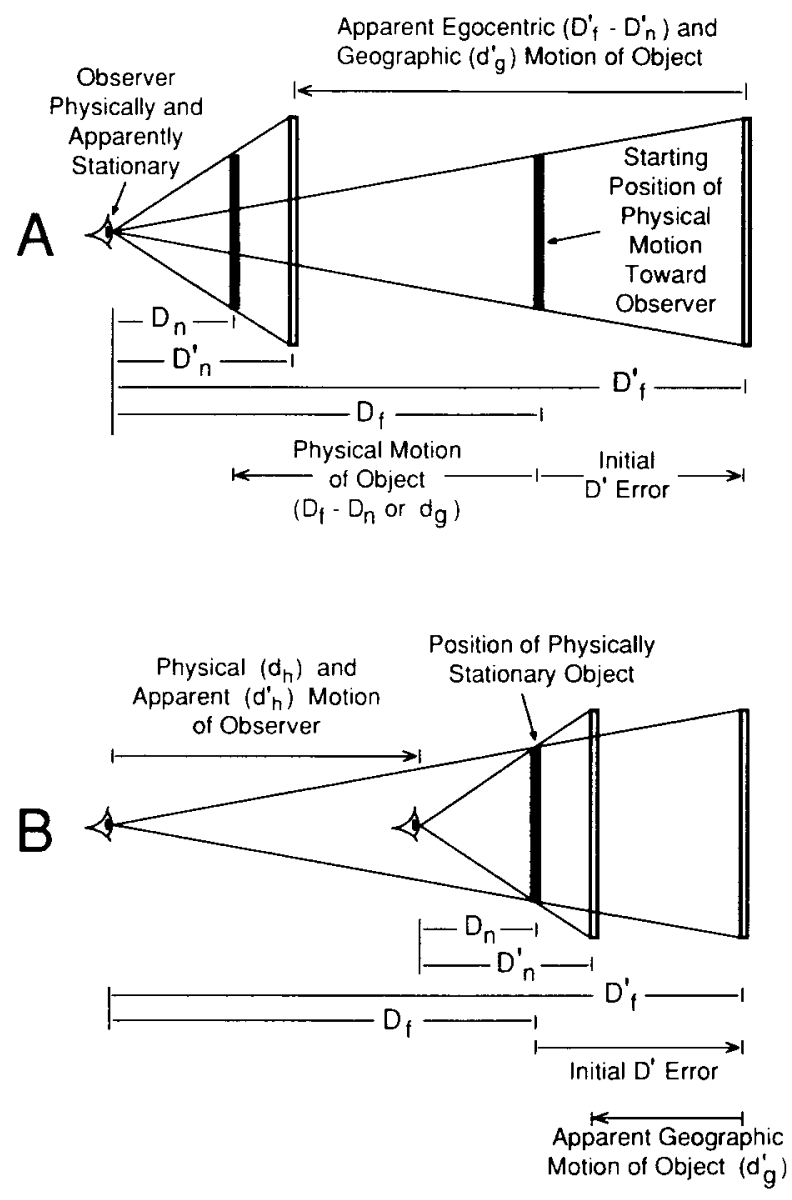

Figure 2. In A, a rectangular stimulus object moves physically (the solid bars) between $D_{\mathrm{f}}$ and $D_{\mathrm{n}}$, but moves perceptually (the open hars) between $D_{f}^{\prime}$ and $D_{n}^{\prime}$, toward a physically and perceptually stationary observer. In B, the stimulus object is physically stationary and the observer's head moves sagittally through the same physical distance as the stimulus moved in $A$. The overestimation of the perceived distances of the stimulus, as measured in Situation A, results in the physically stationary stimulus object in Situation B appearing to move geographically toward the observer as the observer moves toward the stimulus object. 

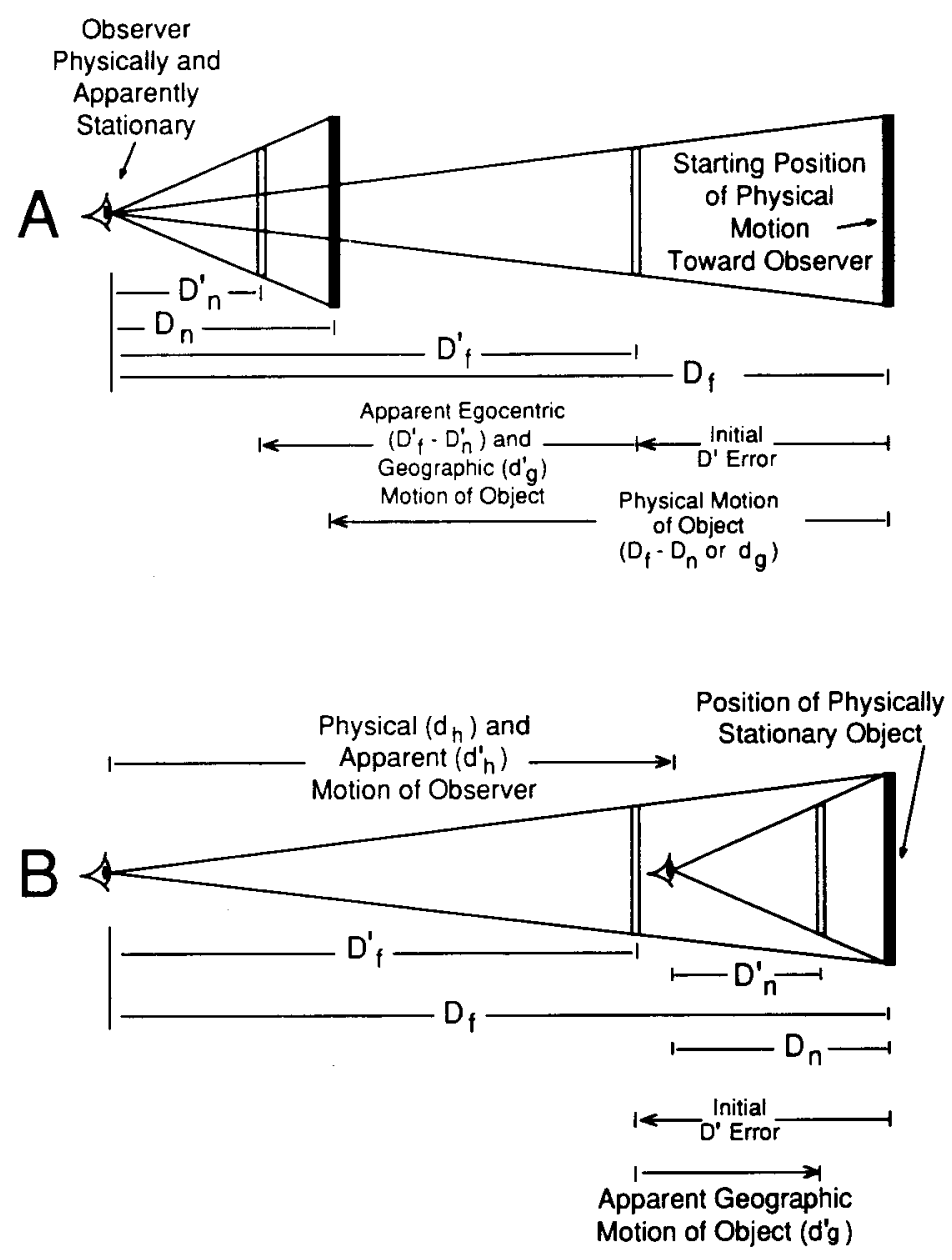

Figure 3. In A, a rectangular stimulus object moves physically (the solid bars) between $D_{\mathrm{f}}$ and $D_{\mathrm{n}}$ but moves perceptually (the open bars) between $D_{\mathrm{f}}^{\prime}$ and $D_{\mathrm{n}}^{\prime}$, toward a physically and perceptually stationary observer. In $B$, the stimulus object is physically stationary and the observer's head moves sagittally through the same physical distance as the stimulus moved in A. The underestimation of the perceived distances of the stimulus, as measured in Situation A, results in the physically stationary stimulus in Situation B appearing to move geographically away from the observer as the observer moves toward the object.

ever, the result that would be expected if the starting distance physically at $D_{\mathrm{f}}$ were perceived to be at $D_{\mathrm{f}}^{\prime}$ where $D_{\mathrm{f}}^{\prime}>D_{\mathrm{f}}$, thereby producing an initial error of the perceived starting distance. In this case, the object would be perceived as moving through an increased distance $\left(D_{\mathrm{f}}^{\prime}-\right.$ $\left.D_{\mathrm{n}}^{\prime}\right)$ at an increased speed. ${ }^{1}$ The error in the perceived distance of the object would be expected to decrease as the object physically moved closer to the observer from $D_{\mathrm{f}}$ to $D_{\mathrm{n}}$. Presumably the object would be perceived as reaching the observer at the same time (the time of impact) as it would have in the absence of the perceived error in the starting distance.

Consider the situation of Figure 2B. Here the object is physically stationary, whereas the observer moves toward the object at the same speed and through the same distance as occurred with the physical motion of the ob- ject toward the observer in Figure 2A; that is, $d_{\mathrm{h}}$ in Figure 2B equals $D_{\mathrm{f}}-D_{\mathrm{n}}$ in Figure 2A. Suppose, in Figure $2 \mathrm{~B}$, that the perceived distance of the object, $D_{\mathrm{f}}^{\prime}$, at the start of the observer's motion toward the object is the same as in Figure 2A. If we assume that the observer's own motion is correctly perceived and that the cues of changing egocentric distance are equally effective in the situations of Figures $2 \mathrm{~A}$ and $2 \mathrm{~B}$, the perceived motion of the physically stationary object will be as is indicated in Figure 2B. To produce the same change in visual egocentric distance information (proximal stimulus) in the situations of Figures $2 \mathrm{~A}$ and $2 \mathrm{~B}$, the starting $\left(D_{f}\right)$ and ending $\left(D_{n}\right)$ physical distances of the stimulus object from the observer are the same in these two situations. Because of this, it can be hypothesized that the changes in perceived egocentric distance of the stimulus object from the 
observer $\left(D_{\mathrm{f}}^{\prime}-D_{\mathrm{n}}^{\prime}\right)$ also will be the same in the two situations. However, because the change in perceived egocentric distance $\left(D_{\mathrm{f}}^{\prime}-D_{\mathrm{n}}^{\prime}\right)$ in Figures $2 \mathrm{~A}$ and $2 \mathrm{~B}$ is larger than the perceived sagittal motion of the head $\left(d_{\mathrm{h}}^{\prime}\right)$ in Figure $2 \mathrm{~B}$, the physically stationary stimulus object will appear to move $\left(d_{\mathrm{g}}^{\prime}\right)$ in Figure 2B opposite to the direction of the perceived sagittal motion of the observer. In this case, the head movement in Figure 2B, even though perceived correctly, cannot compensate for the perceptual effect of the errors in the distance cues between the observer and the object, and the observer perceives the physically stationary stimulus object as moving in geographic space.

Figure 3 illustrates the same factors as those in Figure 2, except that the error in the perception of the far starting distance is in the opposite direction $\left(D_{\mathrm{f}}^{\prime}<D_{\mathrm{f}}\right)$. This, as can be seen in Figure $3 \mathrm{~A}$, results in the perception of the object as moving sagittally $\left(D_{\mathrm{f}}^{\prime}-D_{\mathrm{n}}^{\prime}\right)$ at less than its physical speed and through less than its physical distance. This error in perceived egocentric distance and thus in the perceived sagittal motion of the stimulus object in Figure 3A provides the prediction that, in the matched visual conditions of Figures $3 A$ and $3 B$, the physically stationary stimulus object in Figure 3B will appear to move sagittally $\left(d_{\mathrm{g}}^{\prime}\right)$ in the same direction as the motion of the head.

Throughout the present study, situations in which the head is physically stationary as the stimulus object sagittally moves toward and away from the head (Figures $2 \mathrm{~A}$ and $3 A$ ) will be called Situation A. Situations in which the head sagittally moves toward and away from the stimulus object, which either is physically stationary (as in Figures $2 \mathrm{~B}$ and $\mathrm{3B}$ ) or is physically moving sagittally so as to produce the same changes in visual cues of distance and thus the same changes in perceived egocentric distance as in Situation A, will be called Situation B.

In quantifying the perceived sagittal motion, $d_{\mathrm{g}}^{\prime}$, of the stimulus object, a convention must be established regarding the sign (positive or negative) of the terms used in the figures that is consistent with their relationships. The perception of egocentric sagittal motion between $D_{\mathrm{f}}^{\prime}$ and $D_{\mathrm{n}}^{\prime}$ (i.e., $D_{\mathrm{f}}^{\prime}-D_{\mathrm{n}}^{\prime}$ ) is always positive, since " $\mathrm{f}$ " refers to the farthest (largest) and " $n$ " to the nearest (smallest) perceived egocentric distance of the stimulus. Also, the perceived direction of the head motion in Situation B will always be taken as positive. In the case illustrated in Figure 1 , in which a perceived lateral motion of the stimulus object, $W^{\prime}$, occurs concomitantly with the lateral motion of the head, the convention has been used to take $W^{\prime}$ as positive or negative, depending on whether it is perceived to be in the same direction as, or opposite in direction to, the perceived direction of the lateral motion of the head, respectively. Since research can involve situations in which the perceived motion contains both lateral and sagittal components, it was decided to retain this same general convention in the case of sagittal motion. In the present study, $d_{\mathrm{g}}^{\prime}$ in Situation $\mathrm{B}$ will be taken as positive if it is in the same direction as the sagittal motion of the head (Figure 3B) and as negative if it is in a direction opposite to the sagittal direction of the head motion (Figure $2 B$ ). Because the head is perceptually stationary in Situation $\mathrm{A}$, the same sign criterion regarding $d_{\mathrm{g}}^{\prime}$ cannot be applied. Instead, as is indicated by the direction of the arrow in both Figures $2 \mathrm{~A}$ and $3 \mathrm{~A}, d_{\mathrm{g}}^{\prime}$ is taken as negative, so that, in Situation $A, D_{\mathrm{f}}^{\prime}-D_{\mathrm{n}}^{\prime}=-d_{\mathrm{g}}^{\prime}$. It should be noted that, although $D_{\mathrm{f}}^{\prime}-D_{\mathrm{n}}^{\prime}$ is assumed to be identical in Situations A and B, $d_{\mathrm{g}}^{\prime}$ does not have the same magnitude in the two situations. Given these conventions, it follows in both Figures 2 and 3 that

$$
d_{\mathrm{h}}^{\prime}+D_{\mathrm{n}}^{\prime}-d_{\mathrm{g}}^{\prime}=D_{\mathrm{f}}^{\prime},
$$

or,

$$
d_{\mathrm{h}}^{\prime}-\left(D_{\mathrm{f}}^{\prime}-D_{\mathrm{n}}^{\prime}\right)=d_{\mathrm{g}}^{\prime},
$$

where $D_{\mathrm{f}}^{\prime}-D_{\mathrm{n}}^{\prime}$ is measured in Situation $A$ and is assumed to equal $D_{\mathrm{f}}^{\prime}-D_{\mathrm{n}}^{\prime}$ in the matched Situation $\mathrm{B}$, and $d_{\mathrm{g}}^{\prime}$ is measured in Situation B. The perceived head motion, $d_{\mathrm{h}}^{\prime}$, in Figures $2 \mathrm{~B}$ and $3 \mathrm{~B}$ is assumed for the sake of convenience to equal the physical head motion, $d_{\mathrm{h}}$. The significant variable is $d_{\mathrm{h}}^{\prime}$, not $d_{\mathrm{h}}$, whether or not $d_{\mathrm{h}}^{\prime}=d_{\mathrm{h}}$. According to Equation 4, if it so happened that $d_{\mathrm{h}}^{\prime}=0$ in Situation B even though $d_{\mathrm{h}}>0$, the perception of the sagittal motion of the stimulus object would be expected to be identical to that in Situation A. In that case, $d_{\mathrm{g}}^{\prime}$ in both Situations $\mathrm{A}$ and B would equal $D_{\mathrm{f}}^{\prime}-D_{\mathrm{n}}^{\prime}$.

One possible view of compensation is that $100 \%$ of compensation for head motion requires that a stationary object appear stationary (a veridical perception) as the head moves sagittally. According to Equation 4 and Figures 2 and 3 , a veridical perception of object motion will not occur if $D_{\mathrm{f}}^{\prime}-D_{\mathrm{n}}^{\prime}$ differs from $d_{\mathrm{h}}^{\prime}$, perhaps as a consequence of an error in perceived egocentric distance at the start of the head motion. A different criterion that allows the degree (percent) of compensation for head motion to be calculated will be applied to the present experiments. This criterion is that complete $(100 \%)$ compensation $o c-$ curs whenever the physical motion of the head is completely taken into account. It is derived from Equation 4, in which $\left[\left(D_{\mathrm{f}}^{\prime}-D_{\mathrm{n}}^{\prime}\right)+d_{\mathrm{g}}^{\prime}\right] / d_{\mathrm{h}}^{\prime}=1$ under the condition that $d_{\mathrm{h}}=d_{\mathrm{h}}^{\prime}$, as is illustrated in Figures 2 and 3. That is,

$$
\% \text { compensation }=100\left[\left(D_{\mathrm{f}}^{\prime}-D_{\mathrm{n}}^{\prime}\right)+d_{\mathrm{g}}^{\prime}\right] / d_{\mathrm{h}} \text {, }
$$

where $D_{\mathrm{f}}^{\prime}-D_{\mathrm{n}}^{\prime}$ is obtained from Situation $\mathrm{A}$, and $d_{\mathrm{g}}^{\prime}$ is obtained from Situation B. A third criterion that is entirely consistent with Equation 4 is that complete (100\%) compensation occurs whenever the perceived motion of the head is completely taken into account. It is as follows:

$$
\% \text { compensation }=100\left[\left(D_{\mathrm{f}}^{\prime}-D_{\mathrm{n}}^{\prime}\right)+d_{\mathrm{g}}^{\prime}\right] / d_{\mathrm{h}}^{\prime} .
$$

Equation 6 cannot be applied to the results from the present experiments, since an independent measure of $d_{\mathrm{h}}^{\prime}$ was not obtained.

Figures 2 and 3 also illustrate the necessary distinction between the perception of egocentric distance changes $\left(D_{\mathrm{f}}^{\prime}-D_{\mathrm{n}}^{\prime}\right)$ and geographic sagittal motion of the stimulus object $\left(d_{\mathrm{g}}^{\prime}\right)$. Perceived egocentric sagittal motion is the per- 
ceived sagittal motion of the stimulus object with respect to the observer. Perceived geographic sagittal motion is the perceived sagittal motion of the stimulus object with respect to an unmoving portion of the environment. Unlike in Situation B, in Situation A either $D_{\mathrm{f}}^{\prime}-D_{\mathrm{n}}^{\prime}$ or $d_{\mathrm{g}}^{\prime}$ can be used to represent the perceived motion of the stimulus object, because in Situation A the head is physically and perceptually a stationary part of the environment. Thus, $D_{\mathrm{f}}^{\prime}-D_{\mathrm{n}}^{\prime}$ as measured in Situation A, besides being used to represent the same perceived egocentric motion between head and object in both Situations A and B, also can be used to represent the magnitude of the geographic motion $\left(-d_{g}^{\prime}\right)$ of the object in Situation A. However, $d_{\mathrm{g}}^{\prime}$, unless noted to the contrary, will represent the perceived geographic motion of the stimulus object only in Situation B.

Figures 2 and 3 are hypothetical examples of errors in perceived sagittal motions resulting from errors in the perceived distance of a two-dimensional (extended) object; the errors in the perceived distances are consistent with a constant error in the perceived size of the object. Although the changes in the physical $\left(D_{\mathrm{f}}-D_{\mathrm{n}}\right)$ and perceived $\left(D_{\mathrm{f}}^{\prime}-D_{\mathrm{n}}^{\prime}\right)$ egocentric distances differ from each other, their values are the same in Situation B and in Situation $A$. It is to be expected that the principles of perceived sagittal motion involved in these hypothetical examples will apply to the perception of the sagittal motion of points of light as well as extended objects and to any errors in perceived egocentric distance regardless of their cause. In the present experiments, a single binocularly fused point of light was used as the stimulus object, and changes in oculomotor cues or binocular disparity provided information regarding egocentric distance. The experiments were designed to examine the perception of geographic sagittal motion of the stimulus object diagramed in Figures 2 and 3.

\section{EXPERIMENT 1}

One purpose of Experiment 1 was to determine whether, in general agreement with the hypothetical example of Figure $2 \mathrm{~B}$, a physically stationary point of light, observed binocularly in an otherwise dark surround, would appear to move sagittally opposite to the perceived direction of the head motion when it appeared at a greater distance than its physical distance. A second purpose was to calculate the magnitude of the compensation process, using Equation 5. The factor used to produce the required error in perceived distance was the specific distance tendency. This is a tendency for an object in the presence of only partially effective cues to its distance to be perceptually displaced from its physical distance toward a perceived distance of several meters from the observer (Gogel, 1969; Gogel \& Tietz, 1973). The resulting perceived distance is expected to be some compromise between the physical distance as specified by the partially effective cues-that is, oculomotor cues of accommodation and convergence in the present experiment-and the distance defined by the specific distance tendency. The lateral head motion procedure illustrated in Figure 1 was used to measure the apparent distance of the stimulus point in order to determine that the specific distance tendency had indeed modified the perceived egocentric distance of the stimulus. If one assumes that the observer correctly perceives the magnitude of the head motion $\left(K^{\prime}=K\right)$ and the change in direction to the stimulus $\left(\phi^{\prime}=\phi\right)$ as the head is moved laterally, the apparent lateral motion $\left(W^{\prime}\right)$ of a physically stationary object at a physical distance $(D)$ can be used to determine its perceived distance $\left(D^{\prime}\right)$, as specified by Equation 2 (Gogel, 1982).

\section{Method}

\section{Observers}

The observers in each of the four experiments of this study were 12 graduate students from the psychology department who were paid for their participation. Some of the observers were the same in the different experiments. ${ }^{2}$ All had a visual acuity in both eyes of at least 20/20 and a stereoscopic acuity of at least 18.02" of arc as measured on a Keystone Orthoscope. None were informed about the purpose of an experiment prior to their participation.

\section{Apparatus}

Display conditions. The stimulus was a single $0.7-\mathrm{mm}$ pinhole illuminated from behind by an incandescent grain of wheat lamp and viewed with both eyes. The brightness of the stimulus was 1.3 log units above foveal threshold, measured from the observer's position by a 47 -year-old male after 15 min of dark adaptation. Except for this point of light, the visual alley, including the observation position, was completely dark. The observer sat on a stool in front of a large viewing aperture with a shutter that was used to present or occlude the stimulus. In Situation A, the stimulus moved sagittally and repetitively $16.5 \mathrm{~cm}$ between a distance of 25.0 and $41.5 \mathrm{~cm}$ toward and away from the physically stationary head (the near condition). Or the stimulus moved sagittally between a distance of 102.5 and $119.0 \mathrm{~cm}$ toward and away from the physically stationary head (the far condition). In Situation B, the head moved sagittally and repetitively $16.5 \mathrm{~cm}$ between distances of 25.0 and $41.5 \mathrm{~cm}$ toward and away from the physically stationary stimulus (the near condition). Or the head moved sagittally $16.5 \mathrm{~cm}$ between distances of 102.5 and $119.0 \mathrm{~cm}$ toward and away from the physically stationary stimulus (the far condition). The measures of perceived lateral motion $\left(W^{\prime}\right)$ concomitant with a lateral motion of the head and the measures of perceived egocentric or geographic sagittal motion $D_{\mathrm{f}}^{\prime}-D_{\mathrm{n}}^{\prime}$ or $d_{\mathrm{z}}^{\prime}$ were always obtained as soon as possible after the shutter was closed to occlude the stimulus. The change in the convergence of the eyes required to fixate the point of light as a result of the sagittal motion of the stimulus in Situation $A$ or as a result of the sagittal motion of the head in Situation B were identical. These convergence changes were $5.50^{\circ}$ (i.e., $13.89^{\circ}-$ $8.39^{\circ}$ ) for the near condition and $0.65^{\circ}$ (i.e., $4.05^{\circ}-3.40^{\circ}$ ) for the far condition, as computed from the average interpupillary distance of the observers $(6.1 \mathrm{~cm})$.

While the observer made observations, the observer's head was in a chinrest. The chinrest was mounted on ball bearing rollers, which were guided by a system of tracks that permitted the observer to move the head either sagittally through $16.5 \pm .25 \mathrm{~cm}$ or laterally through $11.5 \pm .25 \mathrm{~cm}$ by grasping a handle attached to the underside of the carrier to which the chinrest was attached. The motions were limited by resilient rubber stops. For the sagittal head motions, the chinrest was always pinned at the midpoint of the lateral motion path. For the lateral head motion, the observer removed the locking pin and held the chinrest against the forward sagittal 
stop as directed, while moving from side to side in the chinrest. An auditory metronome, which produced a click once every $2.4 \mathrm{sec}$, was used to time the arrival at the stops for both sagittal and lateral motion of the head. Potentiometers geared to both the lateral and the sagittal axes of motion and connected to an IBM-PC-compatible computer's 12-bit A/D converter allowed the experimenter to constantly monitor the observer's head position on a display monitor visible only to the experimenter.

The sagittal motion of the stimulus point toward and away from the stationary head in Situation A was accomplished by mounting the luminous point on a platform that could be pushed toward or away from the observer by the experimenter. The platform was mounted on wheels that moved along a track so that it always remained in the observer's midsagittal plane when the head was at the center of the lateral motion path. The experimenter moved the platform as smoothly as possible to arrive at stops along its path separated by $16.5 \pm 0.25 \mathrm{~cm}$. The rate of this motion approximated the rate at which the observer moved the head in the sagittally moving head condition.

Measuring the perceived lateral and sagittal motion of the stimulus point. To obtain measures of the magnitude of the perceived lateral motion of the stimulus point (in order to compute $D^{\prime}$ from $W^{\prime}$ by applying Equation 2), a response device was used; it consisted of two sliding metal posts, which the observer separated laterally by touch to indicate the magnitude of the perceived geographic lateral motion $\left(W^{\prime}\right)$ of the stimulus as the head was moved repetitively left and right through $11.5 \mathrm{~cm}$. The magnitude of the perceived geographic sagittal motion $\left(d_{k}^{\prime}\right)$ of the stimulus object in either Situation A or Situation B and the magnitude of the perceived egocentric sagittal motion $\left(D_{\mathrm{f}}^{\prime}-D_{\mathrm{n}}^{\prime}\right)$ in Situation $\mathrm{A}$ was measured by having the observer adjust the sagittal separation between vertical posts to equal the particular sagittal motion perceived. For this purpose, the two metal posts used in the lateral adjustment were brought together and moved sagittally as a unit toward and away from a third (stationary) metal post extending downward $3.0 \mathrm{~cm}$ in front of the forward position of the head. The movable posts were $1.25 \mathrm{~cm}$ square in cross section and $10 \mathrm{~cm}$ in length, with the top ends located approximately $30 \mathrm{~cm}$ below eye level. The stationary post in the sagittal measure was always nearer than the other two posts. The lateral and sagittal separations of the posts were recorded by the computer by means of potentiometers interfaced to the computer's A/D board. All of the posts were located directly below the surface of the alley on which the stimulus was presented, and none were visible to the observer. The viewing of the stimulus point of light throughout the experiment was binocular.

\section{Procedure}

Prior to the experiment, a small model was used to illustrate sagittal and lateral perceptions of motion and the use of the posts to measure the magnitude of the motions perceived. The instructions emphasized that the responses were always to reflect motions as perceived. The observer was asked to indicate the direction and magnitude of the perceived motion of the stimulus, whether sagittal or lateral, with respect to a portion of the stationary environment, thereby producing perceptual measures of geographic motion. For the response of sagittal geographic motion, this portion of the environment was specified to be the unseen wall in the observation booth directly behind the observer's head. For the response of lateral geographic motion concomitant with a lateral motion of the head, this portion of the environment was the unseen left wall of the experimental alley.

Half of the observers received the near stimulus condition, in which $25.0 \mathrm{~cm}$ was the nearest distance of the stimulus, before they received the far condition, in which $102.5 \mathrm{~cm}$ was the nearest distance of the stimulus, and half received the reverse order. Half were presented with Situation A before Situation B, and half received the reverse order. For any stimulus presentation and for either a sagittal or a lateral response, a verbal report of the perception of the direction of perceived motion relative to the stationary reference was followed by a magnitude response using the measurement posts. The verbal direction report indicated to the experimenter whether the phase of the perceived motion of the stimulus was in the same direction as or opposite to the direction of the head motion. Both a sagittal and a lateral response (always in that order) were obtained before the next stimulus condition was presented. Each kind of response was presented twice in two consecutive trials before the other kind of response was obtained.

\section{Results}

\section{Measures of Perceived Sagittal Geographic Motion $\left(d_{g}^{\prime}\right)$ of the Stimulus}

The mean results from Experiment 1 are shown in Table 1. In Situation A, the head was physically (and, it is assumed, perceptually) stationary. Because of this, the perceived geographic sagittal motion $\left(d_{g}^{\prime}\right)$ of the stimulus object and the perceived egocentric motion $\left(D_{\mathbf{f}}^{\prime}-D_{\mathbf{n}}^{\prime}\right)$ between the far perceived egocentric distance and the near perceived egocentric distance of the stimulus object were identical in size, but, according to the convention discussed previously, they were taken as being opposite in sign (i.e., $D_{\mathrm{f}}^{\prime}-D_{\mathrm{n}}^{\prime}=-d_{\mathrm{g}}^{\prime}$ in Situation A). In Situation B, because the head was physically (and, it is assumed, perceptually) moving, $d_{\mathfrak{g}}^{\prime}$ refers only to the perceived geographic sagittal motion of the stimulus object, since, as is illustrated in Figures 2 and 3, in Situation B, $d_{\mathrm{B}}^{\prime}$ is not equal in extent to $D_{\mathrm{f}}^{\prime}-D_{\mathrm{n}}^{\prime}$. From the information displayed on the experimenter's monitor (invisible to the observer) and the verbal direction report, the perceived motion of the physically stationary point of light in Situation $\mathrm{B}$ could be compared in direction to the physical motion of the head. As has been discussed, because $D_{\mathrm{f}}^{\prime}$ is always the larger and $D_{\mathrm{n}}^{\prime}$ the smaller of the two perceived terminal egocentric distances of the motion, $D_{\mathrm{f}}^{\prime}-D_{\mathrm{n}}^{\prime}$ is always positive. In Situation A, throughout this study, the average perceived egocentric motion was always in the same direction as the physical motion. The negative sign of the average value of perceived geographic sagittal motion $\left(d_{g}^{\prime}\right)$ of the physically stationarya point in the right half of Table 1 indicates that in Situation $B$ the perceived direction of motion of the point was opposite to the direction of the physical motion of the head. As the head physically moved forward, away from the wall behind the observer, the physically stationary point appeared to move toward this wall. As the head physically moved backward, toward the wall behind the observer, the physically stationary point appeared to move away from this wall. This occurred and was statistically significant at least at the .001 level for both the near and the far conditions (averages of $d_{\mathrm{g}}^{\prime}$ of -11.2 and $-6.0 \mathrm{~cm}$, respectively, as shown in Table 1). It will be noted from Figure 2B that such motions opposite to the direction of perceived motion of the head can occur for the case in which the perceived distance of the object exceeds its physical distance. This is the direction of the error in perceived distance expected from the effect of the specific distance tendency for both the near and the far conditions. 
Table 1

Results in Centimeters from Experiment 1. In Situation A, $D_{f}^{\prime}-D_{n}^{\prime}$ is the Perceived Egocentric Motion of the Stimulus Object and $-d_{z}^{\prime}$ is Its Perceived Geographic Sagittal Motion. In Situation B, $d_{z}^{\prime}$ is the Perceived Geographic Sagittal Motion of the Stimulus Object. In Both Situations $A$ and B, $W^{\prime}$ is the Perceived Lateral Motion of the Stimulus Object as Viewed With a Laterally Moving Head, and $D_{\mathrm{n}}^{\prime}$ as Computed From $W^{\prime}$ is the Perceived Egocentric Distance of the Stimulus Object at its Closest Distance to the Observer.

\begin{tabular}{ccccccc}
\hline \multicolumn{2}{c}{ Situation A (Stationary Head, Moving Point) } & & \multicolumn{3}{c}{ Situation B (Moving Head, Stationary Point) } \\
\hline Perceived & Perceived & Perceived & & Perceived & Perceived & Perceived \\
Sagittal Motion & Lateral Motion & Distance & & Sagittal Motion & Lateral Motion & Distance \\
$\left(D_{\mathrm{f}}^{\prime}-D_{\mathrm{n}}^{\prime}\right.$ or $\left.-d_{\mathrm{g}}^{\prime}\right)$ & $\left(W^{\prime}\right)$ & $\left(D_{\mathrm{n}}^{\prime}\right.$ from $\left.W^{\prime}\right)$ & & $\left(d_{\mathrm{g}}^{\prime}\right)$ & $\left(W^{\prime}\right)$ & $\left(D_{\mathrm{n}}^{\prime}\right.$ from $\left.W^{\prime}\right)$ \\
\hline
\end{tabular}

\begin{tabular}{|c|c|c|c|c|c|c|}
\hline \multicolumn{7}{|c|}{ Near Condition } \\
\hline & \multicolumn{3}{|c|}{ Point Motion Between 25.0 and $41.5 \mathrm{~cm}$} & \multicolumn{3}{|c|}{ Point Distance $25 \mathrm{~cm}$} \\
\hline$M$ & 19.0 & -8.8 & 44.1 & -11.2 & -8.3 & 43.1 \\
\hline$S D$ & 4.6 & 6.4 & 13.9 & 6.7 & 6.7 & 14.5 \\
\hline$t$ & 14.2 & 4.8 & 11.0 & 5.8 & 4.3 & 10.3 \\
\hline$p$ & .000 & .001 & .000 & .000 & .001 & .000 \\
\hline \multicolumn{7}{|c|}{ Far Condition } \\
\hline & \multicolumn{4}{|c|}{ Point Motion Between 102.5 and $119.0 \mathrm{~cm}$} & \multicolumn{2}{|c|}{ Point Distance $102.5 \mathrm{~cm}$} \\
\hline$M$ & 8.7 & -6.3 & 158.8 & -6.0 & -5.8 & 154.3 \\
\hline$S D$ & 5.6 & 3.8 & 33.8 & 4.6 & 3.5 & 31.2 \\
\hline$t$ & 5.4 & 5.8 & 16.3 & 4.6 & 5.7 & 17.1 \\
\hline$p$ & .000 & .000 & .000 & .001 & .000 & .000 \\
\hline
\end{tabular}

Note-The data from which the means were calculated are the average of two consecutive, identical trials for each observer. All probability $(p)$ values listed in the tables and text of this study are rounded to the third decimal place. Thus, $p=.000$ means that the probability is $<.0005$.

The criterion for the percentage of compensation in Experiment 1 and in the following experiments is that of applying Equation 5 to determine the degree to which the physical motion of the head is taken into account in the perception of the geographic sagittal motion of the stimulus object in Situation B. For the near condition of Experiment 1 , the substitution from Table 1 of $19.0 \mathrm{~cm}$ for $D_{\mathrm{f}}^{\prime}-D_{\mathrm{n}}^{\prime}$ in Situation $\mathrm{A}$ and $-11.2 \mathrm{~cm}$ for $d_{\mathrm{g}}^{\prime}$ in Situation $B$ results in $47 \%$ compensation. A similar computation for the far condition gives $16 \%$ compensation. These computations are identical to those from a more intuitive calculation in which the decrease in the perceived sagittal motion of the stimulus toward the observer between Situations $A$ and $B$ in Experiment 1 was 7.8 and $2.7 \mathrm{~cm}$ for the near and far conditions, respectively, rather than the $16.5 \mathrm{~cm}$ expected from the physical motion of the head.

\section{Measures of Perceived Egocentric Distance $\left(D^{\prime}\right.$ From $W^{\prime}$ )}

The average perceived distance $\left(D_{\mathrm{n}}^{\prime}\right)$ of the point of light, as computed from $W^{\prime}$ with the use of Equation 2, is also shown in Table 1 . The averages were obtained from the distributions produced by calculating individual values of $D_{\mathrm{n}}^{\prime}$ from $W^{\prime}$, obtained from each observer at the nearest physical distance of the stimulus $(25.0$ or $102.5 \mathrm{~cm}$ ) in the near or far condition. The values of $W^{\prime}$ are negative, because the direction of the perceived lateral motion concomitant with the motion of the head was opposite to the direction of the head motion, indicating, as expected, that the stimulus at 25.0 or $102.5 \mathrm{~cm}$ from the observer was perceived to be at distances greater than these physical distances. The differences between the perceived and physical egocentric distances of the stimuli are consistent with the effect expected from the specific distance tendency. For the near condition, these are 44.1-
$25.0 \mathrm{~cm}=19.1 \mathrm{~cm}$ (Situation A) and $43.1-25.0 \mathrm{~cm}=$ $18.1 \mathrm{~cm}$ (Situation B). For the far condition, they are $158.8-102.5 \mathrm{~cm}=56.3 \mathrm{~cm}$ (Situation A) and $154.3-$ $102.5 \mathrm{~cm}=51.8 \mathrm{~cm}$ (Situation B). The larger effect of the specific distance tendency in the far condition can probably be attributed to the greater cue precision associated with the larger convergences used in the near as opposed to the far condition. The consequence of these errors in perceived distance is that the physically stationary stimulus in Situation B appeared to move sagittally in geographic space, opposite to the direction of the head motion, as is illustrated in Figure 2B. For the same condition (stimulus near or far), the average $D^{\prime}$ from $W^{\prime}$ is expected to be essentially the same in Situations A and B. This occurred for the $D^{\prime}$ values of the near condition (44.1 and $43.1 \mathrm{~cm})$ and also for the far conditions (158.8 and $154.3 \mathrm{~cm}$ ), respectively. This similarity of perceived egocentric distances for Situations A and B is consistent with the assertion, as previously noted, that the visual egocentric cues determining the perceived distances between the observer and stimulus are the same in Situations A and $B$.

Three-factor, repeated measures, analyses of variance were applied separately to the $d_{\mathrm{g}}^{\prime}$ and $D_{\mathrm{n}}^{\prime}$ from the $W^{\prime}$ data of Table 1 for the following variables: situation (Situation A vs. Situation B), stimulus distance condition (near vs. far), and trial (first vs. second). For the sagittal motion adjustments $\left(d_{\mathrm{g}}^{\prime}\right)$, the effects of situation $[F(1,11)=$ $19.26, p=.001]$ and distance condition $[F(1,11)=$ $18.59, p=.001]$, as well as the interactions of situation $\times$ distance $[F(1,11)=12.45, p=.005]$ and situation $\times$ trial $[F(1,11)=6.56, p=.028]$, were statistically significant. For the computed values of $D_{\mathbf{n}}^{\prime}$ from $W^{\prime}$, only the effects of distance condition $[F(1,11)=255.84, p=$ $.000]$ and trial $[F(1,11)=5.43, p=.040]$ were statisti- 
cally significant, with $D_{\mathrm{n}}^{\prime}$ from $W^{\prime}$ in the first trial averaging 101.5 and in the second trial $98.6 \mathrm{~cm}$.

\section{Discussion}

It is evident from Experiment 1 that the error in perceived distance, produced by the specific distance tendency and measured by the lateral motion of the head, prevented the observer from perceiving the physically stationary, binocularly fused point as stationary as the head was moved sagittally. This result also reaffirms the effect of the specific distance tendency on perceived distance, even though oculomotor cues of distance were available to provide veridical distance information. In addition, it can be concluded that compensation for the physical motion of the head was far from complete ( $47 \%$ for the near and $16 \%$ for the far distance of the stimulus). The compensation process, in Situation B, failed notably to provide the perception that a physically stationary point of light at an illusory distance was stationary.

\section{EXPERIMENTS 2 AND 3}

In Experiment 1, as in Figures 2 and 3, Situation B consisted of the head moving sagittally toward and away from a physically stationary stimulus. However, compensation for the sagittal motion of the head, if it is to produce veridical perceptions under more general conditions, should also apply when both the head and the stimulus are moving physically with respect to each other at the same time. To produce accurate perceptions of the geographic motion of objects, when both the observer and the object are moving in different directions or in the same direction but with different amounts, the observer must be able to separate the change in egocentric distance produced by the head motion from that produced by the motion of the stimulus. Again, two situations, A and B, were used to investigate this more general problem. In Situation $A$, the perceived sagittal motion of the stimulus was measured when the head was stationary and the stimulus was simulated to move toward and away from the observer. In Situation $B$, the perception of sagittal motion of the stimulus was measured as the stimulus was simulated to move toward and away from the sagittally moving head under conditions in which the total oculomotor cues of changes in egocentric distance between the observer and stimulus were the same in amount and rate as in Situation A. Again, the percentage of compensation associated with the physical sagittal motion of the head in Situation B was measured using Equation 5.

The only difference between Experiments 2 and 3 was in the instructions. In Experiment 2 (which actually was the first experiment completed in this series; see Note 2), when the head was moved either sagittally or laterally, the observers were simply asked to report the perceived direction and magnitude of the sagittal or lateral motion of the stimulus object. Possibly, in Situation B, for example, some observers might have judged the perceived motion relative to their moving heads, whereas others used a stationary environmental reference. To avoid this possible ambiguity, in all the experiments of this study, except the experiment here labeled as Experiment 2, the experimenter obtained the information concerning the phase relation between the perception of head and object motion by imaging the direction of motion of the head on an experimenter's monitor, not visible to the observer, as the observer reported the perceived direction of object motion relative to a stationary wall of the environment. This stationary wall was specified to be the unseen wall behind the observer for the sagittal judgments and the unseen left wall for the lateral judgments. As it turned out, however, the results from Experiments 2 and 3 were essentially identical, and it was concluded that the perceived sagittal motion being measured in Situation B in Experiment 2 was geographic motion as it was in the other experiments.

\section{Method}

Observers

The same 12 observers participated in Experiments 2 and 3.

\section{Apparatus}

Display conditions. The apparatus for producing the stimulus object is shown schematically in Figure 4. The figure indicates the numerical values of physical or convergence distances, not perceived distances, and it is not drawn to scale. The terminal values of the changing convergence distance of the stimulus (a binocularly fused point of light) are shown by the open circles. These are called the simulated distances of the point. The simulated, binocularly fused point of light was produced by two laterally separated physical points of light, as is indicated by the filled circles. The physical points of light were generated at eye level by placing grain-of-wheat bulbs behind two $0.7-\mathrm{mm}$ pinholes that were separated laterally by $5.0 \mathrm{~cm}$ in a frontoparallel plane (shown by the horizontal line connecting the two filled points in Figure 4). The two points of light were mounted on a platform with wheels that could be moved by the experimenter along a track extending in distance from the observer. The pair of laterally separated, physical points of light in Situation A were moved by the experimenter through a physical sagittal distance of $16.5 \mathrm{~cm}$ (between 25 and $41.5 \mathrm{~cm}$ from the observer). In Situation B, the laterally separated, physical points of light were kept at a constant physical location as the observer moved his or her head through $16.5 \mathrm{~cm}$ (between distances of 25.0 and $41.5 \mathrm{~cm}$ ) toward and away from the physically stationary points. Polarizing filters with orthogonal axes were placed in front of the physical points of light and also in a holder in front of the observer's eyes, so that the left point was seen only by the left eye and the right point only by the right eye of the observer. These points, when binocularly fused, produced a simulated point of light moving through a continuously changing simulated distance in either Situation A or Situation B, as shown by the dashed arrows. The convergence distance of the simulated point was always greater than the physical distance of the stimulus. The brightness of the stimulus was $1.3 \mathrm{log}$ units above foveal threshold, measured through the polarizing filters at the observer's position by a 47 -year-old male after $15 \mathrm{~min}$ of dark adaptation.

The simulated sagittal motion of the point was larger in Situation A $(90.8 \mathrm{~cm})$ than in Situation B $(74.3 \mathrm{~cm})$. This is because, in Situation $\mathbf{A}$, the physical position of the laterally separated points was moved $16.5 \mathrm{~cm}$ toward and away from a stationary observer, whereas, in Situation B, the observer, rather than the physical pair of points, moved sagittally through $16.5 \mathrm{~cm}$. In both situations, the change in convergence angle of $1.0^{\circ}$ (between $1.5^{\circ}$ and $2.5^{\circ}$ ) was 


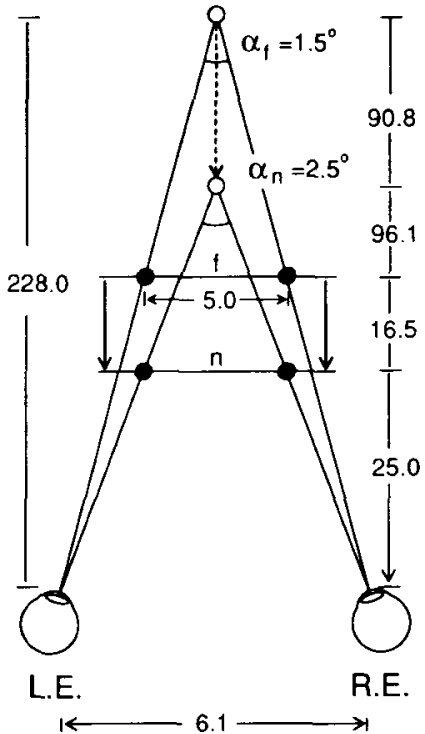

A

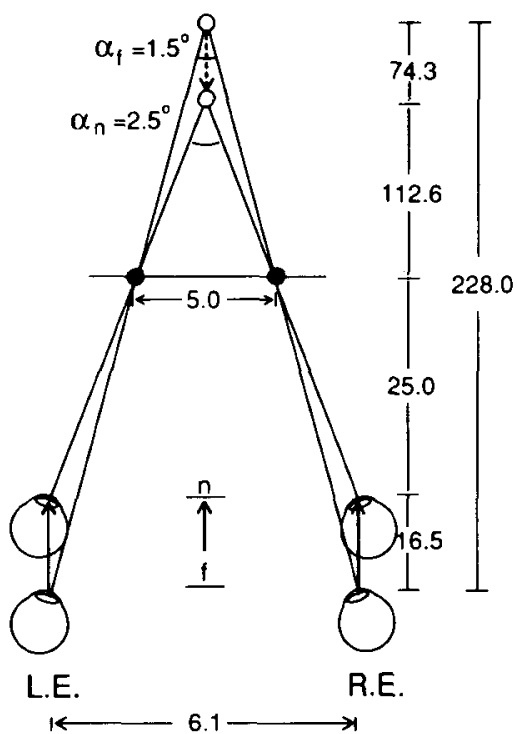

B

Figure 4. A and B are top-view schematic diagrams of the conditions of Experiments 2 and 3 . In $A$, the observer is physically stationary, and each point of the pair of laterally separated points of light (solid circles) moving sagittally through $16.5 \mathrm{~cm}$ is presented by means of polarizing filters to a different one of the two eyes. The binocular fusion of these points by the observer produces a single perceived point (the open circle), which is simulated to move sagittally (the dashed arrow) through $90.8 \mathrm{~cm}$. In B, the pair of physical points of light (solid circles) is physically stationary, and the observer sagittally moves toward the binocularly fused point as the point is simulated to move sagittally through $74.3 \mathrm{~cm}$. The change in distance cues between the observer and object is identical in $\mathbf{A}$ and $\mathbf{B}$, as is indicated in both cases by the convergence change of $1^{\circ}$ between $\alpha_{n}\left(2.5^{\circ}\right)$ and $\alpha_{f}\left(1.5^{\circ}\right)$.

identical, as is indicated in Figure 4. All of the angular change in convergence in Situation $A$ is accounted for by the simulated sagittal motion $(90.8 \mathrm{~cm})$. However, in Situation B, accounting for the same angular change requires the sum of the simulated sagittal motion of the stimulus $(74.3 \mathrm{~cm})$ and the physical sagittal motion of the head $(16.5 \mathrm{~cm})$ - that is, $74.3+16.5 \mathrm{~cm}=90.8 \mathrm{~cm}$. In other words, if the physical motion of the head were fully taken into account, it would reduce the perceived sagittal motion in Situation B from that perceived in Situation A by $16.5 \mathrm{~cm}$.

The simulated convergence distance produced by the polarizing filter apparatus and the lateral separation of the physical points, schematically illustrated in Figure 4, was calculated by the equation

$$
D_{\mathrm{c}}=I D /(I \pm L) \text {, }
$$

where $D_{\mathrm{c}}$ is the convergence distance of the simulated point, $I$ is the interocular distance of the observer, $D$ is the physical distance from the observer of the plane of the laterally separated points of light whose binocular fusion produces the single perceived point, and $L$ is their lateral physical separation. For uncrossed convergence, $-L$ is used, and for crossed convergence, $+L$ is used. The polarizing filter apparatus solves the problem of producing a sagittal stimulus motion in Situation B that is completely coordinated with (concomitant with) the sagittal motion of the observer's head. It is essentially equivalent to continuously adjusting the power of a pair of prisms to produce continuous changes in the convergence in both situations and, in Situation B, to coordinate these changes with the sagittal motion of the head. A disadvantage of using the polarizing filter apparatus, as also would occur if prisms had been used, is that it results in a discrepancy between the accommoda- tion and convergence distance to the stimulus. To reduce this discrepancy, the observer wore an eyeglass frame containing a pair of 2.5 diopter positive spherical lenses. This produced a compromise between the 1.94 and 3.22 diopter lens that would have been required to bring the convergence and accommodation into agreement at the far and near simulated distances, respectively. It was determined from questioning the observers that the lenses prevented any noticeable blurring of the point of light during the experiment. As in Experiment 1, the stimulus was always presented in an otherwise completely dark surround, and it was observed binocularly.

Measuring the perceived sagittal and lateral stimulus motion. The apparatus used for guiding the sagittal and lateral motion of the head and the adjustable posts for measuring the sagittal and lateral perceptions of motion were the same as for Experiment 1. As in Experiment 1, the observers' adjustments of the measurement posts were recorded by a computer.

\section{Procedure}

The procedure for Experiments 2 and 3 was very similar to that for Experiment 1, except for the differences already noted. Again, the order of presenting Situations A and B of Figure 4 was counterbalanced between observers, and, in both situations, a measure of perceived sagittal motion $\left(D_{\mathrm{f}}^{\prime}-D_{\mathrm{n}}^{\prime}\right.$ or $d_{\mathrm{g}}^{\prime}$ in Situation $\mathrm{A}$ and $d_{\mathrm{g}}^{\prime}$ in Situation B) was obtained before obtaining a measure of perceived lateral motion $\left(W^{\prime}\right)$ concomitant with a lateral motion of the head. The measures of $d_{g}^{\prime}$ and $W^{\prime}$ occurred twice in succession for each stimulus condition, and the viewing aperture was always closed during the observer's adjustments of the measuring posts. The perceived measures of lateral motion $\left(W^{\prime}\right)$ in both Situations $A$ and 
B were obtained only when the stimulus was at its farthest simulated distance from the observer $(228.0 \mathrm{~cm})$. The obtained $W^{\prime}$ and, hence, the computed $D^{\prime}$ from $W^{\prime}$ were expected to be the same for Situations $A$ and $B$.

\section{Results}

The average results in centimeters from Experiments 2 and 3 are shown in Table 2. As in Experiment 1, when the head was moved sagittally or laterally, the measure of perceived sagittal or lateral motion with a minus sign in Situation B indicates that this perceived motion was opposite to the direction of the physical sagittal or lateral motion of the head, respectively. In the case of Situation $A$, in which the head did not move sagittally, a sagittal motion of the stimulus point can be interpreted as either an egocentric $\left(D_{\mathrm{f}}^{\prime}-D_{\mathrm{n}}^{\prime}\right)$ or a geographic $\left(d_{\mathrm{g}}^{\prime}\right)$ sagittal motion, since these are identical except for sign, with $D_{\mathrm{f}}^{\prime}-D_{\mathrm{n}}^{\prime}$ always positive.

As expected, the perceived distance $\left(D_{\mathrm{f}}^{\prime}\right.$ from $\left.W^{\prime}\right)$ of the stimulus at its simulated distance of $228.0 \mathrm{~cm}$ from the observer was essentially the same from Situations A and $B$ and also was very similar in Experiments 2 and 3 . These values of $D_{\mathrm{f}}^{\prime}$, however, were less than the simulated distance of $228.0 \mathrm{~cm}$. Perhaps this is to be expected, since the effectiveness of the convergence cue to egocentric distance is likely to fall off considerably for a convergence (simulated) distance this far from the observer. The average perceived sagittal motion from Situation $A$ $\left(D_{\mathrm{f}}^{\prime}-D_{\mathrm{n}}^{\prime}\right.$ or $\left.-d_{\mathrm{g}}^{\prime}\right)$ was very similar in extent in Experiments 2 and $3(24.7$ and $25.3 \mathrm{~cm})$ and $d_{\mathrm{g}}^{\prime}$ in Situation B, as obtained from Experiments 2 and 3, also was essentially the same $(-21.6$ and $-21.2 \mathrm{~cm})$.

Analyses of variance were applied separately to the perceived sagittal data $\left(d_{g}^{\prime}\right)$ and to the perceived egocentric distances $\left(D_{f}^{\prime}\right)$ computed from the individual measures of $W^{\prime}$, using Equation 2 . In both analyses, the variables were Experiment 2 versus Experiment 3, Situation A versus Situation B, and first versus second trial. For the per- ceived sagittal measures $\left(d_{\mathrm{g}}^{\prime}\right)$, the sign shown as $-d_{\mathrm{g}}^{\prime}$ in Table 2, Situation A, was reversed so that the magnitude of the perceived sagittal motion toward and away from the stationary head in Situation A could be compared with that shown as obtained in Situation B. The only significant effect on $d_{\mathrm{g}}^{\prime}$ was that of Situation A versus Situation B $[F(1,11)=7.90, p=.017]$, with the average $d_{\mathrm{g}}^{\prime}$ from Situation A $(-25.0 \mathrm{~cm})$ different from that from Situation B $(-21.4 \mathrm{~cm})$, indicating some small but statistically significant amount of compensation for head motion. For the perceived distance results $\left(D^{\prime}\right.$ from $\left.W^{\prime}\right)$, the only significant effect obtained was an interaction among all three variables $[F(1,11)=5.77, p=.035]$. The similarity in the $D_{\mathrm{f}}^{\prime}$ from $W^{\prime}$ results from Situations $\mathrm{A}$ and $\mathrm{B}$ at the largest simulated distance was expected, since they were simply measures of the perceived egocentric distance obtained from the same $(228.0-\mathrm{cm})$ far simulation of egocentric distance.

\section{Discussion}

Since the results from Experiments 2 and 3 and the results from the first and second trials were quite similar and statistically not significantly different, they can be averaged over Situation A or B and over first and second trials, as shown by the average means of Table 2 . The overall mean $D_{\mathrm{f}}^{\prime}$ from $W^{\prime}$ from Situation A $(131.1 \mathrm{~cm})$ and Situation $B(127.9 \mathrm{~cm})$ was greater than the physical distance of the laterally separated physical points $(41.5 \mathrm{~cm})$ in either Situation A or Situation B but less than the farthest simulated distance $(228.0 \mathrm{~cm})$. Also, in Situation $\mathrm{A}$, the overall mean $D_{\mathrm{f}}^{\prime}-D_{\mathrm{n}}^{\prime}(25.0 \mathrm{~cm})$ in Table 2 was greater than the $16.5-\mathrm{cm}$ physical motion of the horizontally separated points but less than the simulated sagittal change of $90.8 \mathrm{~cm}$. However, the convergence changes having perceptual consequences are those indicated by the changes in simulated distances, not by the physical distances of the laterally separated points, which

Table 2

Results in Centimeters from Experiments 2 and 3. In Situation $A, D_{\mathrm{f}}^{\prime}-D_{\mathrm{n}}^{\prime}$ is the Perceived Egocentric Motion of the Stimulus Object and $-d_{z}^{\prime}$ is Its Perceived Geographic Sagittal Motion. In Situation B, $d_{z}^{\prime}$ is the Perceived Geographic Sagittal Motion of the Stimulus Object. In Both Situations $A$ and $\mathbf{B}, W^{\prime}$ is the Perceived Lateral Motion of the Stimulus Object as Viewed with a Laterally Moving Head, and $D_{f}^{\prime}$ as Computed From $W^{\prime}$ is the Perceived Egocentric Distance of the Stimulus Object at its Farthest Distance From the Observer.

\begin{tabular}{|c|c|c|c|c|c|c|}
\hline & \multicolumn{3}{|c|}{ Situation A (Stationary Head, Moving Point) } & \multicolumn{3}{|c|}{ Situation B (Moving Head, Stationary Point) } \\
\hline & $\begin{array}{c}\text { Perceived } \\
\text { Sagittal Motion } \\
\left(D_{\mathrm{f}}^{\prime}-D_{n}^{\prime} \text { or }-d_{\S}^{\prime}\right)\end{array}$ & $\begin{array}{c}\text { Perceived } \\
\text { Lateral Motion } \\
\left(W^{\prime}\right) \\
\end{array}$ & $\begin{array}{c}\text { Perceived } \\
\text { Distance } \\
\left(D_{\mathrm{f}}^{\prime} \text { from } W^{\prime}\right) \\
\end{array}$ & $\begin{array}{c}\text { Perceived } \\
\text { Sagittal Motion } \\
\left(d_{g}^{\prime}\right)\end{array}$ & $\begin{array}{c}\text { Perceived } \\
\text { Lateral Motion } \\
\left(W^{\prime}\right)\end{array}$ & $\begin{array}{c}\text { Perceived } \\
\text { Distance } \\
\left(D_{\mathrm{f}}^{\prime} \text { from } W^{\prime}\right)\end{array}$ \\
\hline \multicolumn{7}{|c|}{ Experiment 2} \\
\hline$M$ & 24.7 & -24.4 & 129.7 & -21.6 & -23.3 & 125.5 \\
\hline$S D$ & 6.0 & 6.9 & 25.0 & 6.9 & 7.2 & 26.1 \\
\hline$t$ & 14.3 & 12.2 & 18.0 & 10.9 & 11.2 & 16.7 \\
\hline$p$ & .000 & .000 & .000 & .000 & .000 & .000 \\
\hline \multicolumn{7}{|c|}{ Experiment 3} \\
\hline$M$ & 25.3 & -25.2 & 132.5 & -21.2 & -24.6 & 130.3 \\
\hline$S D$ & 4.3 & 4.8 & 17.4 & 5.0 & 5.5 & 19.9 \\
\hline$t$ & 20.2 & 18.1 & 26.4 & 14.7 & 15.5 & 22.7 \\
\hline$p$ & .000 & .000 & .000 & .000 & .000 & 0.000 \\
\hline Average $M$ & 25.0 & 24.8 & 131.1 & -21.4 & -24.0 & 127.9 \\
\hline
\end{tabular}

Note-The data from which the means were calculated are the average of two consecutive, identical trials for each observer. 
were viewed separately by the two eyes as a result of the polarizing filters. Since the visual field was completely dark, except for the binocularly fused point of light, information regarding the physical sagittal distances of the points of light was not sensorially available to the observer. The stimulus conditions in Experiments 2 and 3 (except for some lack of complete equality of accommodation and convergence) in terms of proximal stimulation are equivalent to those of a binocularly observed point of light moving through the simulated convergence distances. Thus, Experiments 2 and 3 are instances of the underperception of egocentric and sagittal motion illustrated in Figure 3. However, unlike in Figure 3, in which the stimulus object in Situation B is represented as physically stationary, in Situation B of Experiments 2 and 3, the stimulus object was simulated to move $74.3 \mathrm{~cm}$ toward or away from the observer as the observer moved toward or away from it by $16.5 \mathrm{~cm}$. Thus, unlike in Figure 3, it was clearly not expected (or obtained) that the perceived geographic motion of the stimulus object would be in the same direction as the head motion. Again, the percentage compensation for the physical head motion, using the overall results from Table 2 and Equation 5 is far from complete-that is, $\mathbf{1 8 . 8 \%}$ and $\mathbf{2 4 . 8 \%}$ from Experiments 2 and 3 , respectively.

\section{EXPERIMENT 4}

It is to be expected that, as the visual cues associated with the perceptions of egocentric distance $\left(D^{\prime}\right)$ and changes in egocentric distance $\left(D_{\mathrm{f}}^{\prime}-D_{\mathrm{n}}^{\prime}\right)$ become increasingly effective, the perceptions of motion will increasingly resemble the physical or simulated motions of the stimulus object, and thus the compensation for the physical head motion will be larger. One purpose of Experiment 4 was to test this expectation. A second purpose was to compare the measurement of the perceived sagittal motion of the stimulus object by two methods. One method is that of the sagittal adjustment of the posts. It was the only method used in Experiments 1, 2, and 3 to measure $D_{\mathrm{f}}^{\prime}-$ $D_{\mathrm{n}}^{\prime}$ or $d_{\mathrm{g}}^{\prime}$. The other method is the lateral head motion procedure, in which the perceived lateral motion, $W^{\prime}$, of the physically stationary stimulus object is used to measure $D^{\prime}$ as in Equation 2. In Experiments 1, 2, and 3, it was used to measure only one of the two terminal positions of the object rather than the magnitude of the perceived object motion. The reason for this restricted use in those experiments was that the lateral head motion procedure, unlike the post adjustment procedure, can measure only one terminal position at a time and then only when the sagittal motion of the object is stopped long enough to execute one or several lateral motions of the head. However, these considerations were not likely to be limiting in Experiment 4, in which the binocular disparity cue between the stimulus object and the visual field was present to specify effectively the perceived location of the object so that the difference between the terminal locations of the object and the extent of the object motion were identical and remained identical during the applications of the lateral head motion procedure. In addition, the assertion that $D_{\mathrm{f}}^{\prime}-D_{\mathrm{n}}^{\prime}$ is the same in the matched conditions of Situations A and B could be examined by using the lateral head motion procedure in Experiment 4. Since the lateral head motion procedure measures egocentric, not geographic, location or changes in location, it was expected to indicate only the egocentric changes in sagittal position, leaving the geographic motion in Situation B to be measured by the sagittal adjustments of the posts. For both purposes, rather than limiting the distance information to that from oculomotor cues alone, in Experiment 4 , the more effective cues of binocular disparity and a texture gradient were added in the visual field.

\section{Method}

\section{Apparatus}

A schematic diagram of the apparatus used in Experiment 4 is shown in Figure 5. The movable chinrest, sagittal and lateral response posts, and metronome used in Experiments 1, 2, and 3 were also used in Experiment 4 . The stimulus was a disk of white light produced by laterally separating two luminous disks $(2.5 \mathrm{~mm}$ in diameter) generated on a NEC Multisync II monitor, which was connected to an IBM-AT-compatible computer. Appropriately oriented polarizing filters on the monitor and at the observer's viewing position were used to produce a binocularly fused single image of the disk located at a simulated distance either beyond or in front of the distance of the monitor. When the disk was to be at the same distance as the monitor surface, only a single disk was present on the monitor and was observed binocularly without the polarizing filters on the monitor screen. The brightness of this single disk was adjusted to the same brightness as that of the stimulus disks viewed through the polarizing filters (a brightness of $2.2 \mathrm{log}$ units above foveal threshold for a 47 -year-old male after $.5 \mathrm{~h}$ of dark adaptation). On each trial, a computer program presented the left- and right-eye images at the proper lateral separation on the monitor for that observer's interocular separation, in order to produce the required changes in convergence distance.

The alley in which the stimulus disk appeared was constructed of plywood and was lined on four inner surfaces (floor, ceiling, and sides) with a nonuniform, nubbly pile, off-white type of carpet, which commercially is called "Berber." The carpet provided texture for the binocular disparity cue between the carpet pile and the stimulus disk. The seams where the wall, floor, and ceiling met were plainly visible along the entire length of the alley, as were the aperture through which the carpet surfaces were visible and a black wall at the more distant end of the alley. In addition, features of the observation position between the observer and the aperture were dimly visible. The carpeted portion of the alley was $33.0 \mathrm{~cm}$ wide, $7.0 \mathrm{~cm}$ tall, and $66.5 \mathrm{~cm}$ in depth. As is illustrated in Figure 5 , the alley, physically extending vertically above the observer's line of sight, was reflected by means of a partially transmitting, partially reflecting, first-surface mirror slanted at $45^{\circ}$ from the horizontal so that the carpeted surfaces appeared to extend horizontally outward from the observer, whose eye level was midway between the floor and ceiling of the alley. The front edge of the carpeted portion of the alley was optically $52.0 \mathrm{~cm}$ from the observer's eyes when the observer's head was at its most forward position. The monitor producing the disk stimulus was physically located in front of the observer along the observer's straight-ahead line of sight. Only the stimulus disks on the monitor, not the monitor itself, were visible through the partially transmitting mirror, so that the binocularly fused single disk was seen as floating within the surrounding carpeted alley and as centered vertically between 


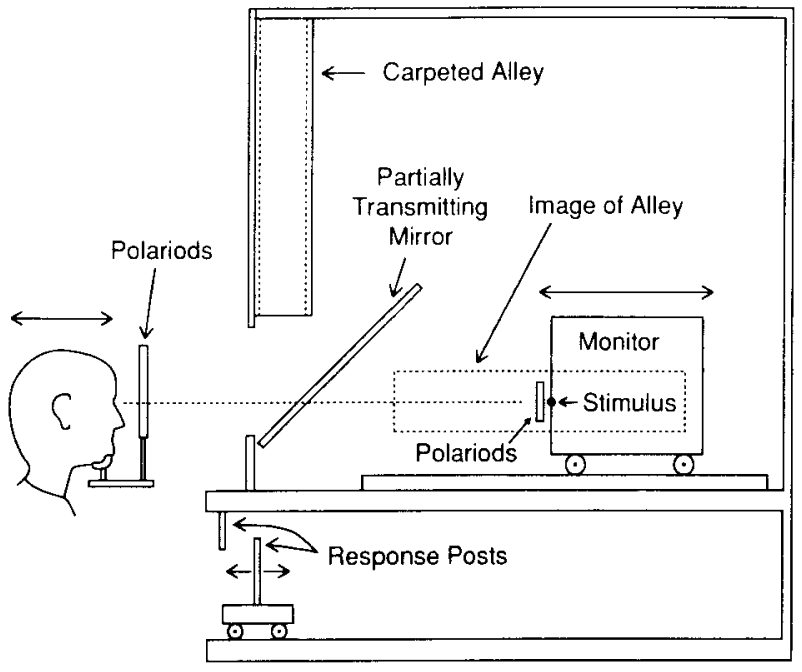

Figure 5. This is a side-view schematic drawing of the apparatus used in Experiment 4. The sagittally movable monitor containing the two points of light to be fused binocularly was physically directly in front of the observer. The fused point was simulated to move in depth midway between the floor and ceiling of the binocularly viewed textured portion of the alley. This textured portion of the alley, physically located above the observer, was reflected by a mirror to appear centered along the observer's line of sight. The sagittal and lateral response posts used in this (and the previous experiments) are represented below the surface along which the monitor could be sagittally moved by the experimenter between cushioned stops. The pair of lateral response posts are represented by the side view of the single nearer post of the pair of sagittal posts, with only the farther post sagittally movable in distance.

the floor and ceiling of the alley and horizontally between the left and right walls, when the observer's head was at the midpoint of the lateral head motion. An incandescent lamp on each side of the alley at the front edge provided illumination along the entire length of the carpeted surfaces. The lamps were masked so that they were not visible to the observer.

\section{Procedure}

As in the previous experiments for producing the sagittally moving stimulus, stationary head situation (Situation A), the simulated and perceived distances of the stimulus (disk) were varied (within the carpeted portion of the alley) by the experimenter, who rolled the monitor on wheels along a track repetitively, directly toward and away from the observer through a constant depth interval of $16.5 \mathrm{~cm}$. This physical sagittal motion of the monitor was between distances of 74.9 and $58.4 \mathrm{~cm}$ (near), 90.2 and $73.7 \mathrm{~cm}$ (middle), or 105.5 and $89.0 \mathrm{~cm}$ (far) from the eyes of the physically stationary observer. The head of the observer was always at its most forward sagittal position during the sagittal motion of the monitor. At each of the three motion intervals of the monitor, three amounts of physical separation of the stimulus disks on the monitor, specified by Equation 7, produced three different convergence distances. This resulted in nine simulated values of sagittal motion of the stimulus disk defined by nine differences in convergence distance between the observer and disk stimulus (values of $D_{\mathrm{cf}}-D_{\mathrm{cn}}$, as shown in Table 3), with three of these resulting from each of the three possible sagittal motions of the monitor.

In Situation B, the observer moved his or her head through a constant sagittal distance of $16.5 \mathrm{~cm}$, with the monitor physically stationary at a distance from the most forward travel of the moving head of $58.4,73.7$, or $89.0 \mathrm{~cm}$. As shown in Table 3, this produced the same nine changes in convergence angle $\left(\alpha_{n}-\alpha_{f}\right)$ and in convergence distance $\left(D_{\mathrm{cf}}-D_{\mathrm{cn}}\right)$ in Situation $\mathrm{B}$ as had been produced in Situation A with the use of the stationary head and moving monitor. These values of convergence localized the disk in the carpeted alley at the distance specified by the particular convergence distance and the portion of the carpeted alley having that same convergence - that is, by the cue of zero binocular disparity between the disk and a small segment of nubbly pile in the carpeted alley. Thus, the changing portions (nubbly pile) of the stationary carpeted alley to which the perceptually moving disk had zero disparity provided highly effective information regarding the simulated sagittal motion of the disk and its simulated static locations.

\section{Predictions}

The differences in simulated convergence distances $D_{\mathrm{cf}}-D_{\mathrm{cn}}$ shown in Table 3, if completely effective, could be used to predict the perception of egocentric sagittal motion of the stimulus object in Situations A and B. Since the head in Situation A, like the geographic environment (e.g., the back wall), was physically stationary, the $D_{\mathrm{cf}}-D_{\mathrm{cn}}$ simulated in Situation A and shown in the second column from the right of Table 3 is predictive of both the change in the perceived egocentric distance $\left(D_{\mathrm{f}}^{\prime}-D_{\mathrm{n}}^{\prime}\right)$ and the perceived geographic motion $\left(d_{\mathrm{g}}^{\prime}\right)$; in Situation $\mathrm{A}$, these are different terms for the same perception but with reversed signs. The values of $16.5-\left(D_{\mathrm{cf}}-D_{\mathrm{cn}}\right)$ shown in the far right column of Table 3 are the simulated geographic sagittal motions $\left(d_{\mathrm{g}}\right)$ of Situation B. If the simulated values shown in both of these columns are the responses obtained in the experiment, the perception of sagittal motion would be accurate. Thus, in the case of veridical perception, the perceived egocentric motion $\left(D_{\mathrm{f}}^{\prime}-D_{\mathrm{n}}^{\prime}\right)$ measured in Situation A would equal the simulated egocentric motion $\left(D_{\mathrm{cf}}-D_{\mathrm{cn}}\right)$, and the perceived geographic motion, $d_{g}^{\prime}$, measured in Situation B would equal the simulated geographic motion, $d_{\mathrm{g}}$, shown in the rightmost column of Table 3. Also, the compensation associated with the physical head motion would be $100 \%$ effective, since the obtained responses $D_{\mathrm{f}}^{\prime}-D_{\mathrm{n}}^{\prime}$ and $d_{\mathrm{g}}^{\prime}$, substituted in Equation 5, would equal the physical motion of the head $(16.5 \mathrm{~cm})$. Because of the binocular disparity and the texture gradient as cues to the sagittal motion of the stimulus disk, it is to be expected that the degree of veridicality and compensation would be greater in this than in the previous three experiments.

\section{Stimulus Categories}

On the basis of the general relations between the simulated and physical stimulus motions, Conditions $a-i$ in Table 3 can be divided into three types (I, II, III), each having a Situation A and B, as diagrammed in Figure 6. In Figure 6, the filled circles represent the position of the stimulus disks on the monitor, and the solid arrows indicate the physical sagittal motion of the monitor in Situation A and the physical motion of the head in Situation B. The simulated sagittal motions of the binocularly fused disk are represented by the dashed arrows and open circles. The large dashed outline rectangles are meant to indicate that the stimulus object appeared within the textured (carpeted) portion of the alley. As discussed previously, the simulated sagittal motions of the stimulus object can be taken as a substitute for physical stimulus motions. Furthermore, suppose it is assumed that the perceptions of distance and motion of the stimulus object and the head are accurate. Then the open circles and dashed arrows of Figure 6 can also be used to predict the direction of the observer's perception of the sagittal motion of the stimulus object in Situations A and B of Experiment 4. Conditions $b, c$, and $f$ are examples of Type $I$ of Figure 6 and are similar in principle to Experiments 2 and 3, except that errors in the perception of the simulated distances or sagittal motions are assumed to be largely absent in Experiment 4 because of the binocular disparity and texture gradient. According to Figure 6, the perceived geographic sagittal motion $\left(d_{g}^{\prime}\right)$ of the disk in Situation B, 
Table 3

Conditions and Simulations in Situations $A$ and $B$ of Experiment 4. Shown Are the Near (n) and Far (f) Physical Sagittal Distances $\left(D_{f}\right.$ and $\left.D_{n}\right)$ of the Monitor From the Observer, the Near (n) and Far (f) Convergence Values $\left(\alpha_{n}\right.$ and $\left.\alpha_{f}\right)$ of the Stimulus Object, the Simulated Convergence Distances $\left(D_{\mathrm{cf}}\right.$ and $\left.D_{\mathrm{cn}}\right)$ of the Stimulus Object as Produced on the Monitor, and the Simulated Geographic Sagittal Motion $\left(d_{z}\right)$ of the Stimulus Object.

\begin{tabular}{|c|c|c|c|c|c|c|c|c|c|c|}
\hline \multirow[b]{2}{*}{ Condition } & \multicolumn{2}{|c|}{$\begin{array}{l}\text { Distance }(\mathrm{cm}) \\
\text { of Monitor } \\
\text { from Observer }\end{array}$} & \multirow{2}{*}{$\begin{array}{c}\begin{array}{c}\text { Motion of } \\
\text { Monitor }(\mathrm{cm}) \\
\text { Situation A }\end{array} \\
D_{\mathrm{f}}-D_{\mathrm{n}}\end{array}$} & \multicolumn{2}{|c|}{$\begin{array}{c}\text { Convergence to } \\
\text { Disk (deg) } \\
\text { Situations A\&B }\end{array}$} & \multirow{2}{*}{$\begin{array}{c}\begin{array}{c}\text { Convergence } \\
\text { Difference (deg) } \\
\text { Situations A\&B }\end{array} \\
\alpha_{n}-\alpha_{\mathrm{f}}\end{array}$} & \multicolumn{2}{|c|}{$\begin{array}{c}\text { Convergence } \\
\text { Distance } \\
\text { to Disk }(\mathrm{cm}) \\
\text { Situations A\&B } \\
\end{array}$} & \multirow{2}{*}{$\begin{array}{c}\text { Simulated } \\
\text { Egocentric } \\
\text { Motion } \\
\text { Situation A } \\
D_{\mathrm{cr}}-D_{\mathrm{cn}} \\
\end{array}$} & \multirow{2}{*}{$\begin{array}{c}\text { Simulated } \\
\text { Geographic } \\
\text { Motion } d_{s} \\
\text { Situation B } \\
16.5-\left(D_{\mathrm{c} f}-D_{\mathrm{cn}}\right)\end{array}$} \\
\hline & $D_{\mathrm{r}}$ & $\overline{D_{\mathrm{n}}}$ & & $\alpha_{n}$ & $\alpha_{\mathrm{f}}$ & & $D_{\mathrm{cf}}$ & $\overline{D_{\mathrm{cn}}}$ & & \\
\hline a & 74.9 & 58.4 & 16.5 & 5.99 & 4.76 & 1.23 & 74.9 & 58.4 & 16.5 & 0.0 \\
\hline b & 74.9 & 58.4 & 16.5 & 4.75 & 3.70 & 1.05 & 94.5 & 73.7 & 20.8 & -4.3 \\
\hline c & 74.9 & 58.4 & 16.5 & 3.93 & 3.07 & .86 & 114.2 & 89.0 & 25.2 & -8.7 \\
\hline d & 90.2 & 73.7 & 16.5 & 5.99 & 4.89 & 1.10 & 71.5 & 58.4 & 13.1 & +3.4 \\
\hline e & 90.2 & 73.7 & 16.5 & 4.75 & 3.88 & .87 & 90.2 & 73.7 & 16.5 & 0.0 \\
\hline $\mathrm{f}$ & 90.2 & 73.7 & 16.5 & 3.93 & 3.21 & .72 & 108.9 & 89.0 & 19.9 & -3.4 \\
\hline g & 105.5 & 89.0 & 16.5 & 5.99 & 5.05 & .94 & 69.2 & 58.4 & 10.8 & +5.7 \\
\hline b & 105.5 & 89.0 & 16.5 & 4.75 & 4.01 & .74 & 87.4 & 73.7 & 13.7 & +2.8 \\
\hline $\mathrm{i}$ & 105.5 & 89.0 & 16.5 & 3.93 & 3.32 & .61 & 105.5 & 89.0 & 16.5 & 0.0 \\
\hline
\end{tabular}

Type I, is expected to be opposite to the direction of the head motion (a negative perceived geographic motion). Conditions $a, e$, and $i$ of Experiment 4 are examples of Type II of Figure 6 and are similar in principle to Experiment 1, but again without the large errors in the perception of the simulated distances. According to Figure 6, the perceived geographic sagittal motion $\left(d_{g}\right)$ of the stationary disk in Situation B, Type II, is expected to be zero. Conditions d, g, and $h$ are examples of Type III, which is not represented in Experiments 1,2 , or 3 . According to Figure 6 , the simulated sagittal geographic motion $\left(d_{\mathrm{g}}^{\prime}\right)$ of the disk in Type III, Situation B, of Experiment 4 is expected to be positive as in Figure 3 (an object motion in the same direction as the head motion).

\section{Results}

\section{Sagittal Adjustments of the Posts}

The average perception of the sagittal motion of the stimulus object, indicated by the sagittal adjustments of the posts, is labeled $D_{\mathrm{f}}^{\prime}-D_{\mathrm{n}}^{\prime}$ or $-d_{\mathrm{g}}^{\prime}$ in Table 4 when measured in Situation $A$ and is labeled as $d_{g}^{\prime}$ when measured in Situation B. The values of $D_{\mathrm{cf}}-D_{\mathrm{cn}}$ are taken from the $D_{\mathrm{cf}}-D_{\mathrm{cn}}$ column of Table 3 for Situation $\mathrm{A}$, and the values of $d_{\mathrm{g}}$ are taken from the $16.5-\left(D_{\mathrm{cr}}-D_{\mathrm{cn}}\right)$ column of Table 3 for Situation $\mathrm{B}$. The $D_{\mathrm{cf}}-D_{\mathrm{cn}}$ and $d_{\mathrm{g}}$ values provide the standard of accurate perceptions of sagittal motion against which the obtained values of $D_{\mathrm{f}}^{\prime}-D_{\mathrm{n}}^{\prime}$ and $d_{\mathrm{g}}^{\prime}$ can be compared. As is shown by the results of $t$ tests in Table 4, all of the average perceived sagittal motions obtained from Situation A differed significantly from zero beyond the .001 level. For Situation B, the average $d_{\mathrm{g}}^{\prime}$ results are as follows. In Conditions $b, c$, and $f$ (Type $I$ ), Situation $B$, the averages are significantly different from zero at, at least, the .001 level, are similar to the simulated values, and, in agreement with Figure 6, are in a direction opposite to that of the motion of the head, as is shown by the negative sign. In Conditions a, e, and i (Type II), Situation B, the average results were expected not to differ significantly from zero. However, in Condition i (an average of $-1.3 \mathrm{~cm}$ ), but not in Conditions a and $e$, the average was significant at the .04 level. In Conditions d, g, and h (Type III), Situation B, although all the averages are positive (in the same direction as the head motion), all are considerably smaller than the simulated values, and only the mean from Condition $\mathrm{g}$ is significantly different from zero (at the .03 level). Although the results from the nine conditions, in general, are consistent with the directions and magnitudes expected from the simulated values, there seems to be some tendency for
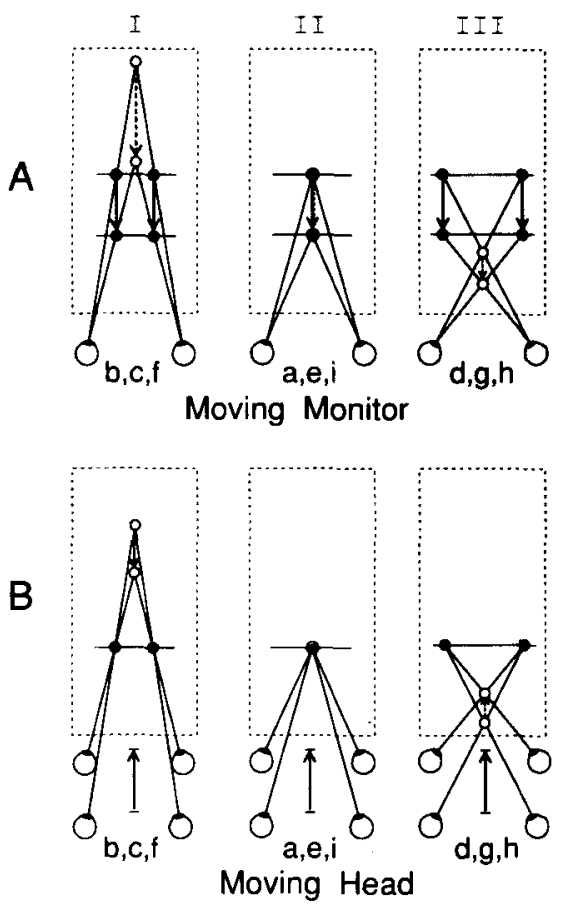

Figure 6. Three types of conditions (I, II, and III) were used in Experiment 4. The filled circles and solid arrows indicate physical objects and motions, the open circles and dashed arrows indicate simulated objects and motions, and the large dotted rectangles indicate the textured part of the visual alley. Each condition had a unique pair of $A$ and $B$ situations in which the change in simulated distance between the observer and stimulus object in a particular pair of situations was always the same. The lowercase letters a through $i$ represent the nine conditions indicated in Table 3 . As is discussed in the text, each type shown in Figure 6 represents three of these conditions. 
the results from Type II, Situation B, to be negative and from Type III, Situation B, to be considerably less positive than predicted from the simulations.

The compensation for physical head motion as specified by Equation 5 was computed by adding to $D_{\mathrm{f}}^{\prime}-D_{\mathrm{n}}^{\prime}$ from Situation A the $d_{\mathrm{g}}^{\prime}$ from Situation B (shown at the bottom of Table 4) and comparing this result with the physical head motion of $16.5 \mathrm{~cm}$. The overall average compensation computed from this process was $80 \%$. As expected, this amount of compensation was larger than that obtained in any of the previous experiments in which the cues of depth and distance were less effective.

\section{Computed Values of $D^{\prime}$ from}

\section{$W^{\prime}$, Applying Equation 4}

The perceived distances of the disk ( $D_{\mathrm{f}}^{\prime}$ and $D_{\mathrm{n}}^{\prime}$ ), averaged over the 12 observers at the farthest $\left(D_{\mathrm{cf}}\right)$ and nearest $\left(D_{\mathrm{cn}}\right)$ convergence distances in Situations $\mathrm{A}$ and $\mathrm{B}$, are shown in Table 5. All of the means $\left(D_{\mathrm{f}}^{\prime}\right.$ and $\left.D_{\mathrm{n}}^{\prime}\right)$ and all but one of the mean differences $\left(D_{\mathrm{f}}^{\prime}-D_{\mathrm{n}}^{\prime}\right)$, calculated from the observer's lateral adjustments of the posts ( $W_{\mathrm{f}}^{\prime}$ and $W_{n}^{\prime}$ ), were statistically different from zero at, at least, the .002 level for both Situation A and Situation B. An analysis of variance of the $D_{\mathrm{f}}^{\prime}$ and $D_{\mathrm{n}}^{\prime}$ data was performed for the variables Situation $\mathrm{A}$ versus Situation $\mathrm{B}$ and $D_{\mathrm{f}}^{\prime}$ versus $D_{\mathrm{n}}^{\prime}$. No significant differences at the .05 level were found between Situations A and B, nor was their interaction significant. As expected, however, $D_{\mathrm{f}}^{\prime}$ was significantly larger than $D_{\mathrm{n}}^{\prime}[F(1,8)=96.86, p=.000]$.

\section{Comparison of Methods of Measuring $D_{\mathrm{f}}^{\prime}-D_{\mathrm{n}}^{\prime}$ and $d_{\mathrm{g}}^{\prime}$}

In Situation A, since the head is stationary, the perceived egocentric motion $\left(D_{\mathrm{f}}^{\prime}-D_{\mathrm{n}}^{\prime}\right)$ and the extent of the perceived sagittal motion $\left(d_{\mathrm{g}}^{\prime}\right)$ of the stimulus object are identical (except for the opposite signs). Therefore, the measurement of $D_{\mathrm{f}}^{\prime}-D_{\mathrm{n}}^{\prime}$ (and $d_{\mathrm{g}}^{\prime}$ ) in Situation A, using the lateral head motion procedure or the sagittal post adjustment procedure, should give identical results though opposite in sign. The graphs of Figure 7, Situation A, show the values of $D_{\mathrm{f}}^{\prime}-D_{\mathrm{n}}^{\prime}$ (or of $-d_{\mathrm{g}}^{\prime}$ ) obtained from the two procedures, plotted against the differences in the convergence distance $\left(D_{\mathrm{cf}}-D_{\mathrm{cn}}\right.$ or $\left.-d_{\mathrm{g}}\right)$ of the stimulus object. In Situation A, the slopes of the lines of best fit (the solid lines) are more like the slopes of the dashed lines (the results expected if the perceived and convergence distances were equal) when the lateral head motion procedure rather than the sagittal post adjustment procedure was used. The lines of best fit are $D_{\mathrm{f}}^{\prime}-D_{\mathrm{n}}^{\prime}=0.90$ $\left(D_{\mathrm{cf}}-D_{\mathrm{cn}}\right)+4.5$ and $D_{\mathrm{f}}^{\prime}-D_{\mathrm{n}}^{\prime}=0.27\left(D_{\mathrm{cf}}-D_{\mathrm{cn}}\right)+$ 10.5 for the former and latter procedures, respectively.

\section{Discussion}

It was expected and found that the $D_{\mathrm{f}}^{\prime}-D_{\mathrm{n}}^{\prime}$ measures were essentially identical in Situations A and B of Experiment 4 , as is shown by the lower two graphs of Figure 7. This was expected, because the amount of change in simulated egocentric distance was the same, whether it was produced by the monitor's moving toward or away from the stationary observer (Situation A) or by the observer's moving toward or away from the stationary monitor (Situation B). The perception of geographic motion, however, was expected and found to be quite different in Situations A and B. This was expected, because all of the changing convergence in Situation A contributed to the perceived geographic sagittal motion, whereas, in Situation $\mathrm{B}$, a substantial portion of the changing convergence was associated with the moving head, thereby decreasing the perceived sagittal motion of the disk. The results from Experiment 4, in comparison with the previous three experiments, showed a substantial increase in the percentage of compensation for physical head motion

Table 4

Results in Centimeters Obtained in Experiment 4 From Measures of the Perceived Sagittal Motion, $D_{\mathrm{f}}^{\prime}-D_{\mathrm{n}}^{\prime}$ or $-d_{k}^{\prime}$, in Situation $A$ and the Perceived Geographic Motion, $d_{k}^{\prime}$, From Situation B as Compared With the Simulated Motions, $D_{\mathrm{cf}}-D_{\mathrm{cn}}$ and $d_{\mathrm{z}}$. All the Perceived Measures Were Obtained by Using the Sagittal Adjustments of the Posts

\begin{tabular}{|c|c|c|c|c|c|c|c|c|c|c|}
\hline & & \multicolumn{9}{|c|}{ Condition } \\
\hline & & a & b & c & d & e & f & g & h & i \\
\hline \multicolumn{11}{|c|}{ Sagitally Moving Disk, Stationary Head (Situation A) } \\
\hline $\begin{array}{l}D_{\mathrm{cf}}-D_{\mathrm{cn}} \text { or }-d_{\mathrm{g}} \\
D_{\mathrm{f}}^{\prime}-D_{\mathrm{n}}^{\prime} \text { or }-d_{\mathrm{g}}^{\prime}\end{array}$ & $\begin{array}{l}M \\
S D \\
t \\
p\end{array}$ & $\begin{array}{c}16.5 \\
13.6 \\
5.1 \\
9.23 \\
.000\end{array}$ & $\begin{array}{c}20.8 \\
16.8 \\
6.8 \\
8.60 \\
.000\end{array}$ & $\begin{array}{c}25.2 \\
16.7 \\
6.3 \\
9.15 \\
000\end{array}$ & $\begin{array}{c}13.1 \\
14.0 \\
5.8 \\
8.37 \\
.000\end{array}$ & $\begin{array}{c}16.5 \\
14.3 \\
6.9 \\
7.13 \\
.000\end{array}$ & $\begin{array}{c}19.9 \\
16.8 \\
7.0 \\
8.30 \\
.000\end{array}$ & $\begin{array}{c}10.8 \\
14.0 \\
5.9 \\
8.18 \\
.000\end{array}$ & $\begin{array}{c}13.7 \\
14.1 \\
6.0 \\
8.17 \\
.000\end{array}$ & $\begin{array}{c}16.5 \\
14.3 \\
4.5 \\
11.11 \\
.000\end{array}$ \\
\hline \multicolumn{11}{|c|}{ Sagittally Moving Head, Stationary Disk (Situation B) } \\
\hline $\begin{array}{l}d_{g} \\
d_{8}^{\prime}\end{array}$ & $\begin{array}{l}M \\
S D \\
t \\
p\end{array}$ & $\begin{array}{c}0.0 \\
-0.7 \\
1.3 \\
1.86 \\
.090\end{array}$ & $\begin{array}{c}-4.3 \\
-4.8 \\
3.4 \\
4.94 \\
.000\end{array}$ & $\begin{array}{c}-8.7 \\
-8.4 \\
4.8 \\
6.04 \\
.000\end{array}$ & $\begin{array}{c}+3.4 \\
+0.3 \\
1.4 \\
0.72 \\
.480\end{array}$ & $\begin{array}{c}0.0 \\
-0.5 \\
1.8 \\
1.00 \\
.340\end{array}$ & $\begin{array}{c}-3.4 \\
-3.9 \\
2.8 \\
4.80 \\
.001\end{array}$ & $\begin{array}{c}+5.7 \\
+2.5 \\
3.4 \\
2.55 \\
.030\end{array}$ & $\begin{array}{c}+2.8 \\
+0.3 \\
3.5 \\
0.33 \\
.750\end{array}$ & $\begin{array}{c}0.0 \\
-1.3 \\
1.9 \\
2.32 \\
.040\end{array}$ \\
\hline \multicolumn{11}{|c|}{ Compensation for Head Motion } \\
\hline $\begin{array}{l}\text { Theoretical } \\
\text { Obtained } \\
\text { Percentage }\end{array}$ & & $\begin{array}{l}16.5 \\
12.9 \\
78\end{array}$ & $\begin{array}{l}16.5 \\
12.0 \\
73\end{array}$ & $\begin{array}{c}16.5 \\
8.3 \\
50\end{array}$ & $\begin{array}{l}16.5 \\
14.3 \\
87\end{array}$ & $\begin{array}{l}16.5 \\
13.8 \\
84\end{array}$ & $\begin{array}{l}16.5 \\
12.9 \\
78\end{array}$ & $\begin{array}{l}16.5 \\
16.5 \\
100\end{array}$ & $\begin{array}{l}16.5 \\
14.4 \\
87\end{array}$ & $\begin{array}{l}16.5 \\
13.0 \\
79\end{array}$ \\
\hline
\end{tabular}


Table 5

Values in Centimeters Obtained in Experiment 4 of the Perceived Distances ( $D_{\mathrm{f}}^{\prime}$ and $D_{\mathrm{n}}^{\prime}$ ) of the Disk From the Observer, at the Far and Near Convergence Distances $\left(D_{\mathrm{cf}}\right.$ and $\left.D_{\mathrm{cn}}\right)$, Using $W_{\mathrm{f}}^{\prime}$ and $W_{n}^{\prime}$ Obtained From the Lateral Head Motion Procedure and Applying Equation 2.

\begin{tabular}{|c|c|c|c|c|c|c|c|c|c|c|}
\hline & & \multicolumn{9}{|c|}{ Condition } \\
\hline & & a & b & c & d & $\mathbf{e}$ & f & g & h & $\mathrm{i}$ \\
\hline & & \multicolumn{9}{|c|}{ Sagitally Moving Monitor, Stationary Head (Situation A) } \\
\hline$D_{\mathrm{cf}}$ & & 74.9 & 94.5 & 114.2 & 71.5 & 90.2 & 108.9 & 69.2 & 87.4 & 105.5 \\
\hline \multirow{2}{*}{$D_{\mathrm{f}}^{\prime}$} & $M$ & 85.9 & 111.9 & 129.6 & 69.6 & 104.3 & 128.4 & 68.1 & 90.4 & 122.7 \\
\hline & $S D$ & 17.6 & 15.2 & 24.4 & 11.4 & 13.7 & 22.0 & 21.3 & 8.3 & 17.6 \\
\hline$D_{\mathrm{cn}}$ & & 58.4 & 73.7 & 89.0 & 58.4 & 73.7 & 89.0 & 58.4 & 73.7 & 89.0 \\
\hline \multirow[t]{2}{*}{$D_{n}^{\prime}$} & $M$ & 64.1 & 88.4 & 101.4 & 54.9 & 84.0 & 107.4 & 53.7 & 70.2 & 108.1 \\
\hline & $S D$ & 9.7 & 11.7 & 10.8 & 11.3 & 14.4 & 14.4 & 24.0 & 11.9 & 19.7 \\
\hline \multirow{4}{*}{$\begin{array}{l}D_{\text {cf }}-D_{\text {cn }} \\
D_{\mathrm{f}}^{\prime}-D_{\mathrm{n}}^{\prime}\end{array}$} & & 16.5 & 20.8 & 25.2 & 13.1 & 16.5 & 19.9 & 10.8 & 13.7 & 16.5 \\
\hline & $\boldsymbol{M}$ & 21.8 & 23.4 & 28.2 & 14.7 & 20.3 & 21.0 & 14.3 & 20.2 & 14.7 \\
\hline & $S D$ & 8.3 & 7.2 & 18.7 & 11.9 & 6.3 & 12.2 & 11.5 & 7.8 & 10.1 \\
\hline & & \multicolumn{9}{|c|}{ Sagittally Moving Head, Stationary Monitor (Situation B) } \\
\hline$D_{\text {cf }}$ & & 74.9 & 94.5 & 114.2 & 71.5 & 90.2 & 108.9 & 69.2 & 87.4 & 105.5 \\
\hline \multirow[t]{2}{*}{$D_{\mathrm{f}}^{\prime}$} & $M$ & 85.7 & 114.1 & 129.1 & 61.8 & 100.8 & 131.2 & 67.5 & 83.8 & 123.5 \\
\hline & $S D$ & 19.4 & 19.7 & 25.5 & 19.9 & 14.1 & 19.9 & 28.2 & 12.4 & 16.1 \\
\hline$D_{\mathrm{cn}}$ & & 58.4 & 73.7 & 89.0 & 58.4 & 73.7 & 89.0 & 58.4 & 73.7 & 89.0 \\
\hline \multirow[t]{2}{*}{$D_{\mathrm{n}}^{\prime}$} & $M$ & 65.3 & 89.3 & 100.5 & 55.5 & 86.1 & 105.2 & 56.2 & 66.0 & 108.9 \\
\hline & $S D$ & 16.0 & 17.4 & 22.2 & 13.8 & 16.5 & 15.4 & 18.1 & 18.2 & 19.7 \\
\hline \multirow{3}{*}{$\begin{array}{l}D_{\mathrm{cf}}-D_{\mathrm{cn}} \\
D_{\mathrm{f}}^{\prime}-D_{\mathbf{n}}^{\prime}\end{array}$} & & 16.5 & 20.8 & 25.2 & 13.1 & 16.5 & 19.9 & 10.8 & 13.7 & 16.5 \\
\hline & $M$ & 20.4 & 24.8 & 28.7 & 6.3 & 14.7 & 25.9 & 11.3 & 17.7 & 14.6 \\
\hline & $S D$ & 6.1 & 6.5 & 11.1 & 7.8 & 8.4 & 10.6 & 18.6 & 8.4 & 9.7 \\
\hline
\end{tabular}

Note-All means are statistically different from zero at (at least) the .002 level, except for the $D_{f}^{\prime}-D_{\mathrm{n}}^{\prime}$ obtained in Condition $\mathrm{g}$, Situation $\mathrm{B}$, where $p=.059$. The $D_{\mathrm{cf}}-D_{\mathrm{cn}}$ shown here and in Table 4 are identical. The $D_{\mathrm{f}}^{\prime}-D_{\mathrm{n}}^{\prime}$ here and in Table 4 are not the same since, as indicated, they were obtained using different measurement procedures.

(an average of $80 \%$, in contrast with $47 \%$ and $16 \%$ in Experiment 1, and with $19 \%$ and $25 \%$ in Experiments 2 and 3). This increase can probably be attributed to the increase in the effectiveness of the cues of depth and distance in Experiment 4, which was due to the addition of binocular disparity between the carpeted portion of the alley and the disk stimulus plus the presence of texture gradient cues provided by the carpet.

Experiment 4 also provides evidence regarding the sensitivity and general validity of the method of measuring perceived egocentric distance by means of the lateral head motion procedure. This is indicated both by the two lower drawings of Figure 7 and the results shown in Figure 8, in which the relation between the convergence distance $\left(D_{\mathrm{c}}\right)$ and the obtained values of $D^{\prime}$ from $W^{\prime}$ are averaged over Situations A and B. It will be recalled that two separate responses, one for $D_{\mathrm{f}}^{\prime}$ and one for $D_{\mathrm{n}}^{\prime}$, occurring at separate times, are required to produce each $D_{\mathrm{f}}^{\prime}-D_{\mathrm{n}}^{\prime}$ difference as obtained from $W_{\mathrm{f}}^{\prime}$ and $W_{\mathrm{n}}^{\prime}$. Despite this, these differences correlate highly with the differences in convergence distance $D_{\text {cf }}-D_{\text {cn }}(r=.86$ in Situation $A$ and .87 in Situation $\mathrm{B}$, as is shown in Figure 7). Also, as is shown in Figure 8, perceived egocentric distance $\left(D^{\prime}\right.$ from $\left.W^{\prime}\right)$ and convergence distance $\left(D_{c}\right)$ were highly correlated $(r=$ .96). However, according to Figure 8 , the obtained value of $D^{\prime}$ from $W^{\prime}$ became progressively more than the convergence distance $\left(D_{c}\right)$ as the convergence distance increased.

\section{GENERAL DISCUSSION}

\section{The Measurement of Compensation \\ for Head Motion}

In Experiments 1, 2, and 3, the computed percentages of compensation for the physical head motions, $d_{h}$, were $47 \%$ (near condition) and $16 \%$ (far condition) in Experiment 1 and $19 \%$ and $25 \%$ in Experiments 2 and 3 . Even in Experiment 4, in eight of the nine conditions, the percentage compensation for the physical head motion, although larger than in Experiments 1, 2, and 3, also was less than $100 \%$. It might be suggested that values of perceived head motion, $d_{\mathrm{h}}^{\prime}$, should have been used in the denominator of the compensation equation (Equation 6) rather than $d_{\mathrm{h}}$ (Equation 5). This would change the calculated compensation from that of the percentage of compensation for the physical head motion to that of the percentage of compensation for the perceived head motion. According to Equation $4, d_{\mathrm{h}}^{\prime}=\left(D_{\mathrm{f}}^{\prime}-D_{\mathrm{n}}^{\prime}\right)+d_{\mathrm{g}}^{\prime}$. When this equation is used, values of $d_{\mathrm{h}}^{\prime}$ for the near and far conditions in Experiment 1 and for Experiments 2 and 3 are $7.8,2.7,3.1$, and $4.1 \mathrm{~cm}$, respectively. The decision to use these values of $d_{\mathrm{h}}^{\prime}$ in Equation 6 would, of course, necessarily have resulted in $100 \%$ compensation for the perceived motion of the head, since the numerator and denominator of Equation 6 in this case would always be identical. Nevertheless, this does suggest that a higher percentage of compensation for head motion might have occurred if 


\section{Situation A Situation B}

\section{Sagittal Post Adjustment Procedure}
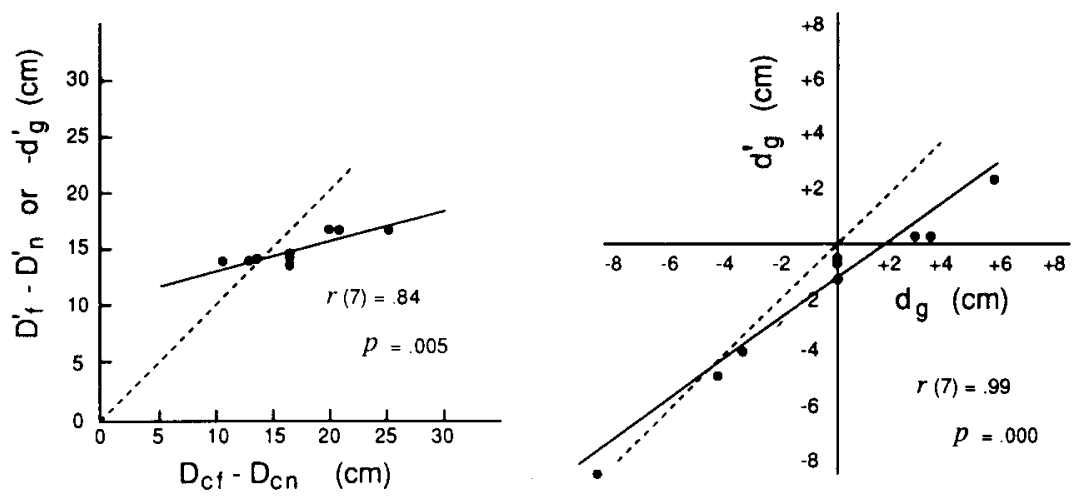

\section{Lateral Head Motion Procedure}
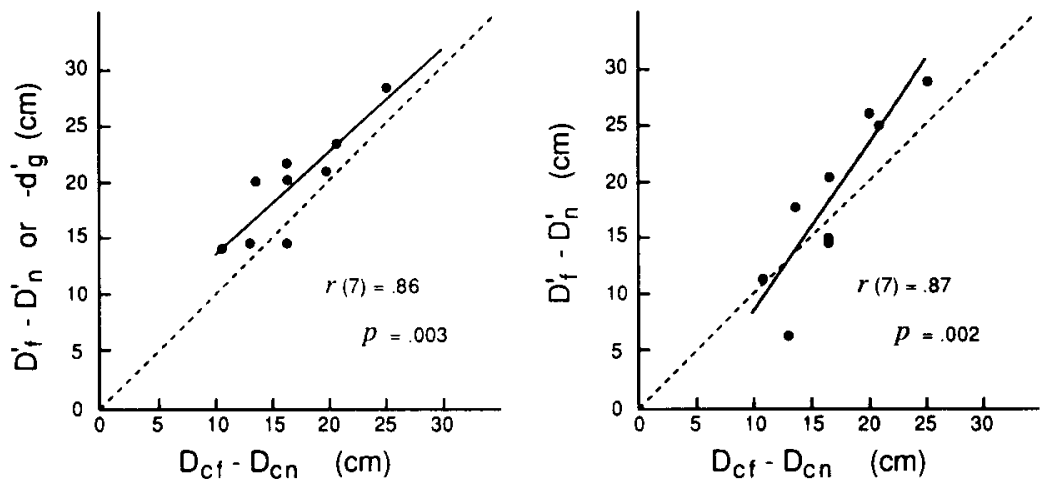

Figure 7. The relation between the simulated egocentric $\left(D_{\mathrm{cf}}-D_{\mathrm{cn}}\right)$ or geographic $\left(d_{\mathrm{z}}\right)$ sagittal motion and the obtained egocentric $\left(D_{f}^{\prime}-D_{n}^{\prime}\right)$ or geographic $\left(d_{z}^{\prime}\right)$ perceptions of sagittal motion of the stimulus object, using the sagittal post adjustment or the lateral head motion procedure in Situations $A$ and $B$ of Experiment 4.

the compensation were defined in terms of a compensation for perceived head motion and if the head motion was greatly underperceived. However, it seems unlikely that values of $d_{\mathrm{h}}^{\prime}$ as small as those calculated from Equation 4 would have been present in Experiments 1, 2, or 3 from a voluntary head motion of $16.5 \mathrm{~cm}$, or that, under identical kinesthetic conditions of head motion, average values of $d_{\mathrm{h}}^{\prime}$ would vary approximately threefold between conditions as in Experiment 1 (between 7.8 and $2.7 \mathrm{~cm}$ ). There is another possibility. It is that the perceived motion of the head, although essentially veridical, had an influence on the perceived motion of the stimulus object that was less than would be expected from the magnitude of the perceived head motion. This possibility will be considered in the following discussion of a theory for explaining the perceived sagittal motion of the stimulus object in Situation B.

\section{Theory}

Hypothesis 1. There are two aspects to be considered in explaining the perception of the sagittal motion of the physically stationary object in Situation B as the head moves sagittally toward this object or both observer and object move sagittally. One is the change in the perceived egocentric distance of the object as determined by the change in the visual cues of egocentric distance between the object and the observer-for example, the cue of changing convergence in Experiments 1,2, and 3. Hypothesis 1, which is also expressed in the discussions of Figures 2 and 3 , asserts that the change in perceived egocentric distance between the object and observer is the same for the same change in visual cues, regardless of whether the change is produced by the motion of the observer, the motion of the stimulus object, or the combined motion of both. This hypothesis can be illustrated with reference to Figures 2 and 3. Because the physical (or simulated) visual change $D_{\mathrm{f}}-D_{\mathrm{n}}$ is identical in Situations $\mathrm{A}$ and $\mathrm{B}$, it can be assumed that the perceived egocentric visual difference $D_{\mathrm{f}}^{\prime}-D_{\mathrm{n}}^{\prime}$ will also be the same in these situations. It is not assumed, however, that $D_{\mathrm{f}}^{\prime}-D_{\mathrm{n}}^{\prime}$ is necessarily equal to $D_{\mathrm{f}}-D_{\mathrm{n}}$. For both Situations A and B, $D_{\mathrm{f}}^{\prime}-D_{\mathrm{n}}^{\prime}$ is greater 


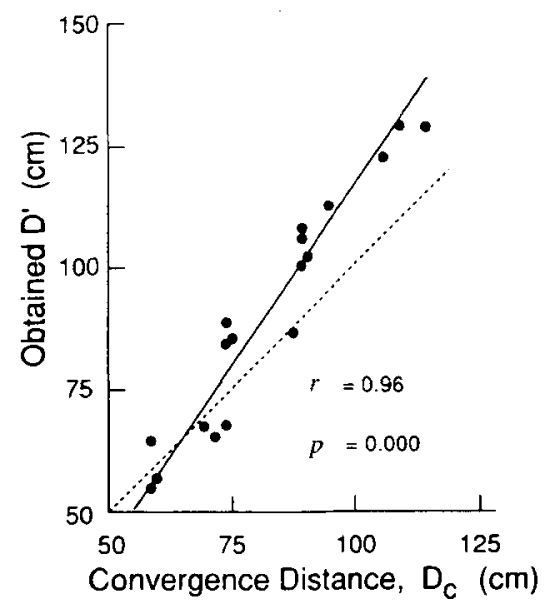

Figure 8. The relation in Experiment 4 between perceived egocentric distance, $D^{\prime}$, of the stimulus object and the convergence distance, $D_{c}$, to the stimulus object, with the former calculated from $W^{\prime}$ of the head motion procedure using Equation 2.

than $D_{\mathrm{f}}-D_{\mathrm{n}}$ in Figure 2 and less than $D_{\mathrm{f}}-D_{\mathrm{n}}$ in Figure 3. Possible reasons why $D_{\mathrm{f}}^{\prime}-D_{\mathrm{n}}^{\prime}$ and $D_{\mathrm{f}}-D_{\mathrm{n}}$ can differ will be discussed. Experiment 4 provides experimental support for Hypothesis 1 , in that for the same $D_{\mathrm{f}}-D_{\mathrm{n}}$ in Situations $\mathrm{A}$ and $\mathrm{B}, D_{\mathrm{f}}^{\prime}-D_{\mathrm{n}}^{\prime}$, measured by the lateral head motion procedure, was also essentially the same in the two sinuations.

Hypothesis 2. As the head moves sagittally toward or away from a stimulus object that is either physically stationary or also physically moving sagittally, the perceived egocentric distance $\left(D^{\prime}\right)$ of the object at a particular instant, since it is a perception between the head (ego) and the object, must be specified at that instant with respect to the perceived position of the head in geographic space. Hypothesis 2 is an expression of that requirement. It states that the perceived egocentric distance $D^{\prime}$ of the stimulus from the observer, at any instant during the head motion, must be measured from the perceived, not the physical, position of the head in geographic space, regardless of whether the perceived and physical positions differ. A figure illustrating the effect on the perceived geographic sagittal motion of the stimulus object of errors in the perceived motion of the head is shown in the Appendix.

Consequences of Hypotheses 1 and 2. Hypotheses 1 and 2 specify constraints that identify two visual components of perceived sagittal motion in Situation B. Consider the case in which the head is moved forward toward the physically stationary stimulus object in Figures 2 and 3, Situation B. As the head moves toward the object, the physical and perceived distances between head and object decrease from $D_{\mathrm{f}}^{\prime}$ to $D_{\mathrm{n}}^{\prime}$. However, by itself, this change between $D_{\mathrm{f}}^{\prime}$ and $D_{\mathrm{n}}^{\prime}$ is nonspecific with respect to whether the head, the stimulus object, or both are moving. During the time that the perceived egocentric distance between head and object is decreasing, the head is moving forward continuously through the perceived geographic distance $d_{\mathrm{h}}^{\prime}$.
This results in a forward motion in geographic space of the perceived position of the reference (the head) from which the perceived egocentric distance $\left(D^{\prime}\right)$ of the stimulus object is measured. Thus, as is indicated in Figures $2 \mathrm{~B}$ and $3 \mathrm{~B}$, as the $D^{\prime}$ between the observer and the object decreases, the perceived movement of the head is producing a component of geographic motion of the object that is opposite to the direction of perceived egocentric change in the distance between the head and object. This component of perceived sagittal motion resulting from the perceived motion of the head is called the perceived tandem component or tandem effect and is labeled $d_{\mathrm{t}}^{\prime}$. It has this name because it is as though the stimulus object (in addition to undergoing simultaneously the perceptual change in egocentric distance specified by $D_{\mathrm{f}}^{\prime}-D_{\mathrm{n}}^{\prime}$ ) were yoked to the head at an essentially constant perceived distance in front of the head. As a result, the stimulus object, in addition to the egocentric component of visually perceived motion, receives a geographic component of visually perceived motion in the same direction as the perceived (felt) motion of the head. As will be discussed, however, there are possible factors that may result in the perceived tandem effect $\left(d_{t}^{\prime}\right)$ not being always identical to the amount of felt motion of the head. The perceived tandem component $\left(d_{\mathrm{t}}^{\prime}\right)$, like $D_{\mathrm{f}}^{\prime}-D_{\mathrm{n}}^{\prime}$, is a visual component that contributes to the perceived visual motion of the stimulus object. Together, $d_{\mathrm{t}}^{\prime}$ and $D_{\mathrm{f}}^{\prime}-D_{\mathrm{n}}^{\prime}$ simultaneously determine the perception of geographic motion, $d_{\mathrm{g}}^{\prime}$, of the stimulus object in Siruation $B$, throughout the duration of the head motion. According to Equation $4, d_{\mathrm{h}}^{\prime}-\left(D_{\mathrm{f}}^{\prime}-D_{\mathrm{n}}^{\prime}\right)=d_{\mathrm{g}}^{\prime}$. Or, more generally, since $d_{t}^{\prime}$ is not necessarily always expected to be equal to $d_{\mathrm{h}}^{\prime}$, and since $d_{\mathrm{t}}^{\prime}$ and $D_{\mathrm{f}}^{\prime}-D_{\mathrm{n}}^{\prime}$ may be in the same as well as in opposite directions, Equation 4 is modified so that

$$
d_{\mathrm{t}}^{\prime} \pm\left(D_{\mathrm{f}}^{\prime}-D_{\mathrm{n}}^{\prime}\right)=d_{\mathrm{g}}^{\prime} .
$$

The expression $d_{\mathrm{t}}^{\prime}-\left(D_{\mathrm{f}}^{\prime}-D_{\mathrm{n}}^{\prime}\right)$ is used whenever $d_{\mathrm{t}}^{\prime}\left(\right.$ or $\left.d_{\mathrm{h}}^{\prime}\right)$ and $D_{\mathrm{f}}^{\prime}-D_{\mathrm{n}}^{\prime}$ are in opposite directions, as occurred in all the experiments of this study - that is, whenever the perceived egocentric distance of the stimulus object decreases as the head moves perceptually toward the object; the expression $d_{\mathrm{t}}^{\prime}+\left(D_{\mathrm{f}}^{\prime}-D_{\mathrm{n}}^{\prime}\right)$ is used whenever $d_{\mathrm{t}}^{\prime}$ and $D_{\mathrm{f}}^{\prime}-D_{\mathrm{n}}^{\prime}$ are in the same direction-that is, whenever the perceived egocentric distance of the stimulus object increases as the head moves perceptually toward the object. An example in which $d_{\mathrm{t}}^{\prime}$ and $D_{\mathrm{f}}^{\prime}-D_{\mathrm{n}}^{\prime}$ would be added to predict $d_{\mathrm{g}}^{\prime}$ in Equation 8 is the case of the perception of the geographic sagittal motion of a rabbit as viewed by a pursuing fox that is steadily losing ground.

The value of $d_{\mathrm{t}}^{\prime}$ can be obtained by measuring the perceived geographic sagittal motion of a stimulus object rigidly attached to the head at a constant physical distance from the head (probably the average of the $D_{\mathrm{f}}$ and $D_{\mathrm{n}}$ used in the corresponding Situations A and B) so as to move in tandem with the head, for the same head motion used in Situation B, In this situation, to be called Situation C, the same egocentric cue or cues of the stimulus object as those in Situations A and B would be used, except that the 
cue or cues would define or simulate a static (constant) rather than a dynamic (changing) distance of the stimulus object from the moving observer.

The contributions of the two components $d_{\mathrm{t}}^{\prime}$ and $D_{\mathrm{f}}^{\prime}-D_{\mathrm{n}}^{\prime}$ can be considered as vectors of motion that together determine $d_{g}^{\prime}$. Such a vector explanation of perceived motion requires no process beyond that of the algebraic summation of perceptions from different sources of information. Also, although each vector is measured as a separate visual perception ( $d_{\mathrm{t}}^{\prime}$ from Situation $C$ and $D_{\mathrm{f}}^{\prime}-D_{\mathrm{n}}^{\prime}$ from Situation $A)$, the vectors merge in Situation $B$ as a single visual perception of geographic sagittal motion. As a result, the observer does not separately perceive the tandem motion that is superposed upon the changing egocentric distance; instead, the observer perceives a moving or stationary stimulus in the visual field in which the observer also perceives himself/herself to be moving or stationary. Vector addition is not uncommon in perception. For example, in induced motion, a vertically moving test point enclosed by a horizontally moving frame will appear to move at a tilt. The vertical and horizontal vectors of this perceived tilt can be determined separately by measuring the lateral induced motion in the absence of a vertical motion of the test object and the vertical perceived motion of the test object in the absence of motion in the inducing object (Gogel, 1979). Or, perhaps more appropriately, the process involved in Equation 8 may have some similarity to the kind of integration involved in a perceptual response to different and sometimes conflicting sensory information regarding distance.

Sources modifying the contribution of $D_{f}^{\prime}-D_{\mathrm{n}}^{\prime}$ or $d_{\mathrm{t}}^{\prime}$ to $d_{\mathrm{g}}^{\prime}$ in Situation B. Each of the factors $d_{\mathrm{t}}^{\prime}$ and $D_{\mathrm{f}}^{\prime}-D_{\mathrm{n}}^{\prime}$ can be independently influenced by a variety of sources of stimulation. But the requirement that this diversity of influences must exert its effect on $d_{\mathrm{g}}^{\prime}$ by modifying the difference between $d_{\mathrm{t}}^{\prime}$ and $D_{\mathrm{f}}^{\prime}-D_{\mathrm{n}}^{\prime}$ simplifies the prediction of the perceptual outcome. A number of the influences that have separate effects on $d_{\mathrm{t}}^{\prime}$ and $D_{\mathrm{f}}^{\prime}-D_{\mathrm{n}}^{\prime}$ can be considered. Since $D_{\mathrm{f}}^{\prime}-D_{\mathrm{n}}^{\prime}$, according to Hypothesis 1 , is the same in Situations $\mathrm{A}$ and $\mathrm{B}$, the factors determining $D_{\mathrm{f}}^{\prime}-D_{\mathrm{n}}^{\prime}$ can be considered as they occur in Situation $A$. One of these is a difference between the physical $\left(D_{\mathrm{f}}-D_{\mathrm{n}}\right)$ and perceived $\left(D_{\mathrm{f}}^{\prime}-D_{\mathrm{n}}^{\prime}\right)$ depth within the motion interval. In general, it has been found that a constant sagittal depth interval (e.g., $D_{\mathrm{cf}}-D_{\mathrm{cn}}$ ) within a configuration will appear to be larger as the perceived distance of the configuration from the observer increases (Gogel, 1964; Ono \& Comerford, 1977; Ono, Rivest, \& Ono, 1986; Wallach \& Zuckerman, 1963). It seems likely that a similar relation holds for changes in depth from, for example, the cue of convergence (Gogel, 1977), particularly when these changes are presented continuously in quite rapid sagittal motion. According to this factor, the perception of sagittal motion, under many circumstances, would be expected to be greater or less than the physical sagittal motion, if the perceived distance of the sagittal motion interval from the observer is greater or less, respectively, than its physical distance. An instance of the former result is diagrammed in Figure 2.
A similar result occurred in Experiment 1, in the near condition, in which the perceived sagittal motion of $19 \mathrm{~cm}$ in Situation A exceeded the physical sagittal motion of $16.5 \mathrm{~cm}$ because of the error in perceived distance resulting from the specific distance tendency. On the other hand, a factor that can produce a decrease in $D_{\mathrm{f}}^{\prime}-D_{\mathrm{n}}^{\prime}$ relative to $D_{\mathrm{f}}-D_{\mathrm{n}}$ rather than an increase is likely to occur if the perception of the sagittal motion interval is supported only by changing oculomotor cues at relatively far distances. The effectiveness of oculomotor cues tends to decrease with increased physical distance, so that at several meters from the observer, their contribution largely, if not totally, disappears. An example is the reduced perceived sagittal motion $(25.0 \mathrm{~cm})$ obtained in Situation A of Experiments 2 and 3 at a relatively far distance from the observer despite the simulated sagittal motion of $90.8 \mathrm{~cm}$. All factors that modify perceived egocentric distance so as to affect the relation between $d_{\mathrm{t}}^{\prime}$ and $D_{\mathrm{f}}^{\prime}-D_{\mathrm{n}}^{\prime}$ are also modifiers of $d_{\mathrm{g}}^{\prime}$.

There are also factors that must be considered in evaluating the contribution of the tandem motion $\left(d_{t}^{\prime}\right)$ to the perception of sagittal geographic motion $\left(d_{\mathrm{g}}^{\prime}\right)$ of the stimulus object. The most important of these is the magnitude of the perceived sagittal motion of the head, which may or may not differ from the physical sagittal head motion. Another is the possibility in Situation B that $d_{\mathrm{t}}^{\prime}$ and $D_{\mathrm{f}}^{\prime}-D_{\mathrm{n}}^{\prime}$ are not equally weighted in determining $d_{\mathrm{g}}^{\prime}$. Differential weighting of different sources of spatial information is not uncommon in perceptual phenomena. For example, in situations in which two distance cues are not in agreement, one may be more effective than the other in contributing to the perception of the distance of the stimulus object. This can occur between as well as within sensory systems. For example, different spatial information from audition and vision often leads to the visual information receiving the greater weight in the resulting perception. This phenomenon, which occurs in various degrees, is known as visual capture. If this happened in the present phenomena between $d_{\mathrm{t}}^{\prime}$ and $D_{\mathrm{f}}^{\prime}-D_{\mathrm{n}}^{\prime}$ (see Equation 8), the differential weighting would be within the visual system and not between proprioceptive $\left(d_{\mathrm{h}}^{\prime}\right)$ and visual $\left(D_{\mathrm{f}}^{\prime}-D_{\mathrm{n}}^{\prime}\right)$ components. This is because the effective tandem motion $\left(d_{t}^{\prime}\right)$, although mainly, if not totally, determined by $d_{\mathrm{h}}^{\prime}$, is a visual rather than a kinesthetic vector. A third factor is whether the tandem component of motion resulting from the perceived motion of the head is always equal to the perceived motion of the head. It is possible, for example, that as the distance of the stimulus object from the observer is increased, the visual contribution of the tandem motion provided by a constant distance cue, perhaps of convergence, may decrease for the same perceived motion of the head until the tandem component of perceived motion may eventually become zero at relatively far distances from the observer. Generally, since $d_{t}^{\prime}$ is essentially a static (constant) visual component, its contribution to $d_{\mathrm{g}}^{\prime}$ for equal values of $d_{t}^{\prime}$ and $D_{\mathrm{f}}^{\prime}-D_{\mathrm{n}}^{\prime}$ might be less than that of the dynamic (changing) component $D_{\mathrm{f}}^{\prime}-D_{\mathrm{n}}^{\prime}$. This might explain why, as the effectiveness of the cues to depth are reduced in Experiments 1,2, and 3 compared with Experiment 4, the amount 
of compensation associated with the same head motion is reduced.

The major contribution of the theory, if valid, is not in limiting the number of factors that may be identified as affecting the perception of geographic object motion as the head is moved. Rather, its value is in the concept that these factors, however numerous, must exert their influence through a relation between the two visual components of $d_{\mathrm{t}}^{\prime}$ and $D_{\mathrm{f}}^{\prime}-D_{\mathrm{n}}^{\prime}$, whether or not the particular relation expressed by Equation 8 is entirely adequate. The theory, by asserting that the process is an integration of two sources of visual information, avoids an interpretation that requires any concepts more complex than those normally associated with the integration of visual information.

Applying the equations to the experimental results. According to Equation 4, the significant factor in the perception of the sagittal motion or stationariness $\left(d_{\mathrm{g}}^{\prime}\right)$ of the stimulus object in Situation B is the relation between $d_{\mathrm{h}}^{\prime}$ and $D_{\mathrm{f}}^{\prime}-D_{\mathrm{n}}^{\prime}$ [e.g., $d_{\mathrm{h}}^{\prime}-\left(D_{\mathrm{f}}^{\prime}-D_{\mathrm{n}}^{\prime}\right)=d_{\mathrm{g}}^{\prime}$ ]. The theory discussed above modifies this equation to state (Equation 8) that $d_{\mathrm{g}}^{\prime}$ is determined by the relation between $d_{\mathrm{t}}^{\prime}$ and $D_{\mathrm{f}}^{\prime}-D_{\mathrm{n}}^{\prime}\left[\right.$ i.e., $\left.d_{\mathrm{t}}^{\prime}-\left(D_{\mathrm{f}}^{\prime}-D_{\mathrm{n}}^{\prime}\right)=d_{\mathrm{g}}^{\prime}\right]$. According to the theory, Equation 8 is preferable to Equation 4 , because it identifies the tandem effect as the means by which the kinesthetic factor, $d_{\mathrm{h}}^{\prime}$, is translated into a visual factor, $d_{\mathrm{t}}^{\prime}$, in order to contribute to the visual perception of the geographic motion $\left(d_{\mathrm{g}}^{\prime}\right)$ of the stimulus object. Since $D_{\mathrm{f}}^{\prime}-D_{\mathrm{n}}^{\prime}$ and $d_{\mathrm{g}}^{\prime}$ are available in the results of the present experiments, they can be used to calculate $d_{\mathrm{h}}^{\prime}$ using Equation 4 or, alternatively, $d_{\mathrm{t}}^{\prime}$ using Equation 8 . As has been discussed, the values of $d_{\mathrm{h}}^{\prime}$ (or $\left.d_{\mathrm{t}}^{\prime}\right)$ as calculated from $D_{\mathrm{f}}^{\prime}-D_{\mathrm{n}}^{\prime}$ $+d_{g}^{\prime}$ using the results from the experiments are substantially less than the $16.5 \mathrm{~cm}$ of physical motion, particularly for Experiments 1, 2, and 3. There are three possible reasons for the smallness of $d_{\mathrm{h}}^{\prime}$ or $d_{l}^{\prime}$ as calculated from Equation 4 or 8: (1) The head motion was underperceived, thus producing a reduced value of $d_{\mathrm{h}}^{\prime}$ and $d_{\mathrm{t}}^{\prime}$. (2) The head motion was correctly perceived, but the transfer of this perceived motion to $d_{\mathrm{t}}^{\prime}$ was less than complete. (3) The head motion was correctly perceived, and its transfer to the tandem motion was complete; but the weight given by the visual system to the tandem motion, in comparison with the weight given to the changing egocentric component of visual motion, was reduced. If this third possibility occurred to any significant degree, a weighting factor would need to be inserted into Equation 8. Or, perhaps more than one of these possibilities was present simultaneously. These possible explanations await studies in which $d_{t}^{\prime}$ as well as $D_{\mathrm{f}}^{\prime}-D_{\mathrm{n}}^{\prime}$ and $d_{\mathrm{g}}^{\prime}$ are all measured in Situations $\mathrm{C}, \mathrm{A}$, and $B$, respectively, and also studies in which the accuracy of sensing the motion of the head $\left(d_{\mathrm{h}}^{\prime}\right)$ is evaluated independently of $d_{t}^{\prime}$.

\section{Some Implications of the Research and Theory}

Implications for the role of compensation. Experiments 1,2 , and 3 suggest that the observer's ability to compensate for the physical sagittal motion of the head in perceiv- ing the geographic sagittal motion or stationariness of the stimulus object is quite limited under relatively reduced conditions of observation. A criterion of compensation in terms of the perceived motion of the head might possibly provide greater compensation. Against this possibility is the small size of the perceived head motion that would be required in this case to explain the results from Experiments 1,2 , and 3 . The phenomena that concepts of compensation are designed to explain perhaps can be better explained in other terms. According to the theory presented here, the perception of sagittal geographic motion of the stimulus, viewed with a sagittally moving head, involves the integration of two visual vectors. One of these is the change in the perceived egocentric distance of the stimulus. The other, occurring often in an opposite direction, is a perceived tandem effect basically associated with the perceived motion of the head.

Interrelations between perceptions. It will be noted that Equation 4 is structurally similar to the equation implied in the right column of Table 3 , in which only physical or simulated terms are used, as follows:

$$
d_{\mathrm{h}}-\left(D_{\mathrm{f}}-D_{\mathrm{n}}\right)=d_{\mathrm{g}} .
$$

Equation 4 and Equation 8 (in which $d_{t}^{\prime}$ is substituted for $d_{\mathrm{h}}^{\prime}$ ) are expressed in perceptual, not physical, terms. As long as the changes in the physical or simulated egocentric distances of the stimulus object $\left(D_{\mathrm{f}}-D_{\mathrm{n}}\right.$ or $\left.D_{\mathrm{cf}}-D_{\mathrm{cn}}\right)$ in Situations $A$ and $B$ and the physical motion of the head $\left(d_{\mathrm{h}}\right)$ in Situation B are the same, they can be disregarded when one is predicting the perception of the geographic sagittal motion of the object in Situation B. It is the perceived, not the physical or simulated magnitudes of tandem and egocentric motion that need to be measured in order to explain the perception of geographic motion. This conclusion receives support, particularly from Experiments 1,2 , and 3 , in that, as expected, errors in the perceived egocentric distance of the object resulted in substantial errors in its perceived geographic motions. Such results are counter to theoretical views that question whether some perceptions can be used to predict others (Baird \& Wagner, 1991; Wallach \& Berson, 1989).

The interrelation between perceptions found in the present study is consistent with a theory of phenomenal geometry (Gogel, 1990) in which phenomenal space is determined by three variables: (1) perceived distance, (2) perceived direction, and (3) the observer's perception of the observer's own motion. These variables specify the location of points in three-dimensional phenomenal space and produce the derived perceived characteristics of size, motion, shape, and orientation. Figure 1 as expressed by Equation 1 provides an example of the phenomenal geometry of perceived motion concomitant with a lateral motion of the head. In the case of the perception of sagittal motion in Situation A or B of the present experiments, there is no variation in the perceived direction to the stimulus object. However, the perception of the egocentric distances of the stimulus object and the perception of the sagittal mo- 
tion of the head remain as factors to explain the perception of the sagittal geographic motion of the stimulus object regardless of whether it is illusory or veridical.

Oculomotor cues of distance. In Experiment 1, Situation A, near condition, the stimulus point of light physically moving sagittally between 41.5 and $25.0 \mathrm{~cm}$, thereby producing a change in vergence and accommodation of $8.5^{\circ}$ and 1.6 diopters, respectively, was perceived to move on the average through $19.0 \mathrm{~cm}$. In Situation A, far condition, the point of light simulating a sagittal motion between 119.0 and $102.5 \mathrm{~cm}$, thereby producing a change in vergence of $0.65^{\circ}$ and 0.14 diopters, respectively, was perceived to move on the average through $8.7 \mathrm{~cm}$. In Experiments 2 and 3 , the stimulus point of light physically moving sagittally between 228.4 and $137.6 \mathrm{~cm}$, thereby producing a change in vergence of $1.0^{\circ}$ and a change in accommodation of 1.6 diopters (as computed from the physical motion) was perceived to move on the average through 24.7 and $25.0 \mathrm{~cm}$ in Experiments 2 and 3, respectively. All of these perceived sagittal motions were significantly different from zero. Oculomotor cues of distance presented dynamically produced clear perceptions of motion in depth. However, it has been found that a small stimulus changing in convergence without concomitant changes in accommodation is unlikely to produce motions in perceived depth as robust as those found in the present study (see Collewijn, Steinman, Erkelens, \& Regan, 1991). Such differences in results seem to suggest that stimulus changes in both convergence and accommodation in the same direction are important in producing perceptions of depth motion. Whether an advantage is obtained for the perception of depth from dynamic (continuous) static (successive) changes of the same magnitude needs to be determined, although such a result might be expected.

Visual kinesthesis. The value of $d_{t}^{\prime}$ in Equation 4 as calculated from the more visually reduced conditions (Experiments 1,2 , and 3) was considerably smaller than that obtained from the conditions with more cues (Experiment 4). This needs to be explained. A major factor contributing to $d_{t}^{\prime}$ is the perception of the magnitude of the sagittal motion of the head, $d_{h}^{\prime}$. If the perceived motion of the head were less than the physical motion of the head in Experiments 1,2, and 3 but approximately equal to the physical motion of the head in Experiment 4, this might explain the change in calculated $d_{1}^{\prime}$ between these experiments. A factor that could possibly increase the $d_{\mathrm{h}}^{\prime}$ in conditions involving a textured area like that in Experiment 4 could be visual kinesthesis, which concerns the idea that the motion of the head relative to the various portions of the surround contributes to the observer's information regarding the magnitude of the head motion (see Gibson, 1958, 1979; Owen, 1990). The application of this possible explanation to the present study involves two assumptions. One is that, under the more reduced conditions, the motion of the head was greatly underperceived, despite the head motion's being voluntarily produced by the observer. But, as noted previously, the amount of underperception of the head motion required for this assumption in Experiments 1, 2, and 3 makes it implausible. A second assumption is that increas- ing the amount of detail found in a partially textured visual field (Experiment 4) compared with that from a single point of light (Experiments 1,2, and 3) would increase the accuracy of the sensing of the head motion. However, a change in visual egocentric distance, no matter how effective the egocentric cues are or how detailed the stimulus is, remains ambiguous with respect to whether the observer, the stimulus, or both are moving. A nonsensory restraint must be added-in this case, perhaps a tendency to perceive an extended and detailed visual field as being stationary (see Andersen, 1990). This restraint is not always effective, however. For example, when one is riding in a moving vehicle, the stationary environment appears to move, with different parts appearing to move different amounts and at different speeds. This is probably caused by the combination of (1) a lack of self-motion information from stimuli arising from within the rider and (2) errors in the perceived distances of parts of the visual field, with neither of these factors necessarily eliminated by the presence of a detailed and extended visual field.

A different explanation consistent with the application of Equation 8 to both reduced and multicue conditions was mentioned previously. It may be that $d_{t}^{\prime}$ for the same amount of head motion is smaller or given less weight in the more reduced conditions than in conditions with more cues because the egocentric cues of changing (dynamic) distance $\left(D_{\mathrm{f}}^{\prime}-D_{\mathrm{n}}^{\prime}\right)$ under rather reduced conditions are more effective than the constant (static) cues associated with the tandem effect $\left(d_{t}^{\prime}\right)$. For the same conditions of object and head motion, an increase in the number and effectiveness of the visual cues to distance such as that which occurred in Experiment 4 may decrease this difference in the effectiveness of static and dynamic cues. As a result, the contributions of $d_{\mathrm{t}}^{\prime}$ and $D_{\mathrm{f}}^{\prime}-D_{\mathrm{n}}^{\prime}$ to the perception of the geographic motion or stationariness of the stimulus object would become more equal, and, consequently, the perception of geographic stimulus motion viewed with the moving head would become more veridical.

However, it is clear that robust effects of visual kinesthesis upon the perceived motion $d_{\mathrm{h}}^{\prime}$ of the head can occur even in the absence of proprioceptive changes from within the observer. This is seen in the induction of self-motion by moving stimuli presented on each side of the head (Kano, 1991). In the case of visually induced sagittal motion of the head, an effect on the perceived sagittal geographic motion of a stimulus located in front of the observer is consistent with the theory of the present study identifying the relation between $d_{\mathrm{t}}^{\prime}$ and $D_{\mathrm{f}}^{\prime}-D_{\mathrm{n}}^{\prime}$ as the significant variable. The increase in $d_{\mathrm{h}}^{\prime}$, provided in this instance by the induction, results in an increase in $d_{t}^{\prime}$ relative to $D_{\mathrm{f}}^{\prime}-D_{\mathrm{n}}^{\prime}$. Suppose, for example, that in Situation A in Figures 2 and 3, visually induced motion were introduced so that the physically stationary head of the observer was perceived to move sagittally by an amount $d_{\mathrm{h}}^{\prime}$. Suppose further that this induced $d_{\mathrm{h}}^{\prime}$ was equal to the $d_{\mathrm{h}}^{\prime}$ in Situation B, where the $d_{\mathrm{h}}^{\prime}$ was produced solely by the physical motion of the head. If this occurred, it would be expected from the theory that the perception of the sagittal geographic stimulus motion, $d_{g}^{\prime}$, in Situation A would 
be the same as that in Situation B. Thus, according to the theory presented here, visual kinesthesis, if it occurs, has its effect on the perception of the geographic motion of the stimulus, $d_{g}^{\prime}$, through its effect on $d_{t}^{\prime}$ as influenced by $d_{\mathrm{h}}^{\prime}$ and the relation between $d_{\mathrm{t}}^{\prime}$ and $D_{\mathrm{f}}^{\prime}-D_{\mathrm{n}}^{\prime}$. But, as long as $D_{\mathrm{f}}^{\prime}-D_{\mathrm{n}}^{\prime}$ is not equal to the contribution from $d_{\mathrm{t}}^{\prime}$, the visual kinesthesis will not result in a correct perception of the geographic sagittal motion of the stimulus. Thus, it is expected that the relation between $d_{\mathrm{t}}^{\prime}$ and $D_{\mathrm{f}}^{\prime}-D_{\mathrm{n}}^{\prime}$ will have the same implications for the perception of geographic sagittal motion of the stimulus, whether the perceived head motion is determined by proprioception from within the observer or by visual kinesthesis.

\section{REFERENCES}

ANDERSEN, G. J. (1990). Segregation of optic flow into object and self-motion components: Foundations for a general model. In R. Warren \& A. H. Wertheim (Eds.), Perception and control of self-motion (pp. 127-141). Hillsdale, NJ: Erlbaum.

BaIRD, J. C., \& WAGNer, M. (1991). Transformation theory of size judgments. Journal of Experimental Psychology: Human Perception \& Performance, 17, 852-864.

Collewijn, H., Steinman, R. M., Erkelens, C. J., \& Regan, D. (1991). Binocular fusion, stereopsis and stereoacuity with a moving head. In D. Regan (Ed.), Binocular vision: Vision and visual dysfunction (Vol. 9, pp. 121-136). New York: Macmillan.

GiBson, J. J. (1958). Visually controlled locomotion and visual orientation in animals. British Journal of Psychology, 49, 182-194.

GiBson, J. J. (1979). The ecological approach to visual perception. Boston: Houghton-Mifflin.

GoGeL, W. C. (1964). The perception of depth from binocular disparity. Journal of Experimental Psychology, 67, 379-386.

GoGEL, W. C. (1969). The sensing of retinal size. Vision Research, 9, 1079-1094.

GoGEL, W. C. (1977). An indirect measure of perceived distance from oculomotor cues. Perception \& Psychophysics, 21, 3-11.

GoGEL, W. C. (1979). Induced motion as a function of the speed of the inducing object, measured by means of two methods. Perception, $8,255-262$.

GOGEL, W. C. (1982). Analysis of the perception of motion concomitant with a lateral motion of the head. Perception \& Psychophysics, 32, 241-250.

GoGel, W. C. (1990). A theory of phenomenal geometry and its applications. Perception \& Psychophysics, 48, 105-123.

Gogel, W. C., \& TIETZ, J. D. (1973). Absolute motion parallax and the specific distance tendency. Perception \& Psychophysics, 13, 284-292.

Kano, C. (1991). The perception of self-motion induced by peripheral visual information in sitting and supine postures. Ecological Psychology, 3, 241-252.

ONO, H., \& COMERford, J. (1977). Stereoscopic depth constancy. In W. Epstein (Ed.), Stability and constancy in visual perception: Mechanisms and processes (pp. 91-128). New York: Wiley.

ONo, M. E., Rivest, J., \& ONo, H. (1986). Depth perception as a function of motion parallax and absolute-distance information. Journal of Experimental Psychology: Human Perception \& Performance, 12, 331-337.

OWEN, D. H. (1990). Lexicon of terms for the perception and control of self-motion and orientation. In R. Warren \& A. H. Wertheim (Eds.), Perception and control of self-motion (pp. 33-50). Hillsdale, NJ: Erlbaum.

Swanston, M. T., \& Gogel, W. C. (1986). Perceived size and motion in depth from optical expansion. Perception \& Psychophysics, 39, 309-326.

WAlLACH, H. (1985, May). Perceiving a stable environment. Scientific American, pp. 118-124.

WALLACH, H. (1987). Perceiving a stable environment when one moves. Annual Review of Psychology, 38, 1-27.

WALLACH, H., \& BERSON, E. (1989). Measurements of the illusion. In M. Hershenson (Ed.), The moon illusion (pp. 287-297). Hillsdale, NJ: Erlbaum.

WALlaCh, H., \& FlaherTy, E. W. (1975). A compensation for field expansion caused by moving forward. Perception \& Psychophysics, $17,445-449$.

Wallach, H., Stanton, L., \& Becker, D. (1974). The compensation for movement-produced changes of object orientation. Perception \& Psychophysics, 15, 339-343.

WALLACH, H., \& ZUCKERMAN, C. (1963). The constancy of stereoscopic depth. American Journal of Psychology, 76, 404-412.

\section{NOTES}

1. In Situations A and B of Figures 2 and 3, the stimulus object is represented as remaining constant in perceived size as it moves sagittally. There are situations in which this is not expected to occur (Swanston \& Gogel, 1986). However, constancy in the perceived size of an extended stimulus object is not a requirement in order for the explanation of the perceived sagittal geographic motion $\left(d_{\mathrm{g}}^{\prime}\right)$ of the stimulus object in Situation B presented here to apply.

2. The four experiments of this study were completed in the order $2,3,1,4$. Seven observers participated in all of the first three experiments, and 8 observers in Experiment 4 were in one or more of the other experiments.

\section{APPENDIX \\ A Glossary of Terms}

$D_{\mathrm{f}} \quad$ Farther physical or simulated egocentric distance of the stimulus object.

$D_{\mathrm{n}} \quad$ Nearer physical or simulated egocentric distance of the stimulus object.

$D_{\mathrm{f}}-D_{\mathrm{n}} \quad$ Difference between the farther and nearer physical or simulated distances.

$D_{\mathrm{cf}} \quad$ Physical or simulated far convergence distance of the stimulus object.

$D_{\mathrm{cn}} \quad$ Physical or simulated near convergence distance of the stimulus object.

$D_{\mathrm{cf}}-D_{\mathrm{cn}} \quad$ Physical or simulated sagittal motion of the stimulus object between the far and near convergence distances.

$\alpha_{\mathrm{f}} \quad$ Physical or simulated angle of convergence to the far distance of the stimulus object.

$\alpha_{n} \quad$ Physical or simulated angle of convergence to the near distance of the stimulus object.

$\alpha_{n}-\alpha_{\mathrm{f}} \quad$ Physical or simulated change in convergence between the near and far distances of the stimulus object.

$d_{\mathrm{g}} \quad$ Physical or simulated sagittal motion of the stimulus object with respect to a stationary

$d_{\mathrm{h}} \quad \begin{aligned} & \text { portion of the environment (physical } \\ & \text { Physical sagittal motion of the head }\end{aligned}$

$D_{\mathrm{f}}^{\prime} \quad$ Farther perceived egocentric distance of the stimulus object. 
$\begin{array}{ll}D_{\mathrm{n}}^{\prime} & \begin{array}{l}\text { Nearer perceived egocentric distance of the stimulus object. } \\ D_{\mathrm{f}}^{\prime}-D_{\mathrm{n}}^{\prime}\end{array} \\ & \begin{array}{l}\text { Difference between the farther and nearer perceived egocentric distances of the stimulus } \\ \text { object. } \\ d_{\mathrm{g}}^{\prime}\end{array} \\ & \begin{array}{l}\text { Perceived sagittal motion of the stimulus object with respect to a stationary portion of the } \\ \text { environment (perceived geographic motion). }\end{array} \\ d_{\mathrm{h}}^{\prime} & \begin{array}{l}\text { Perceived sagittal motion of the head. } \\ d_{\mathrm{t}}^{\prime}\end{array} \\ & \begin{array}{l}\text { Perceived sagittal tandem motion of the test object associated with the perceived sagittal } \\ \text { motion of the head. }\end{array} \\ D^{\prime} \text { from } W^{\prime} & \begin{array}{l}\text { A measure of the perceived egocentric distance of the stimulus object by means of the ap- } \\ \text { parent lateral geographic motion of the stimulus object }\left(W^{\prime}\right) \text { concomitant with a lateral mo- } \\ \text { tion of the head. }\end{array}\end{array}$ Note-The magnitude of $d_{\mathrm{g}}^{\prime}$ in Situation $\mathrm{B}$ is specified by its perceived extent of motion relative to a stationary part of the environment. The sign of $d_{\mathrm{g}}^{\prime}$ is positive if it is in the same perceived direction as the perceived motion of the head and is negative if it is in a perceived direction opposite to that of the perceived motion of the head. It is meaningless to apply the same criterion of sign to $d_{\mathrm{g}}^{\prime}$ in Situation $\mathrm{A}$, since in Situation $\mathrm{A}$ the head is stationary. The direction of $d_{\mathrm{g}}^{\prime}$ in Situation $\mathrm{A}$ is considered negative if the perceived sagittal motion of the stimulus object is in the same direction as its physical motion.

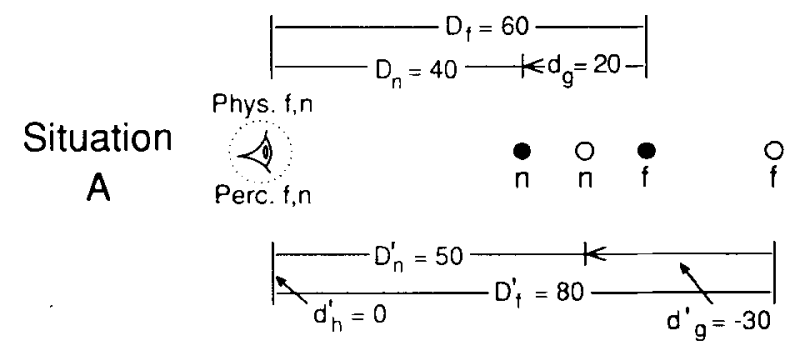

Figure A1. A hypothetical illustration is shown of the effect of errors in the perceived sagittal motion of the head ( $\left.d_{\mathrm{h}}^{\prime}\right)$ upon the perceived geographic sagittal motion of the stimulus object $\left(d_{z}^{\prime}\right)$. The physical and perceived terminal positions (far and near) of head motion are labeled "Phys.f" and "Phys.n," and "Perc.f " and "Perc.n," respectively. The physical and perceived positions of the head are illustrated as the same at the far position of the head but not at the near position in Situations $B_{1}$ and $B_{2}$ (as is indicated by the dotted circles). The physical and perceived terminal positions of the motion of the stimulus object are shown by the solid and open circles, respectively. In Situation $A$, the stimulus moves sagittally. In Situations $B_{1}$ and $B_{2}$, it is physically stationary. Although the physical $D_{f}-D_{n}$ and perceived $D_{f}^{\prime}-D_{\mathrm{n}}^{\prime}$ are different from each other, each is the same in Situation $A$ as it is in the B situations (Hypothesis 1$)$. The terminal $D_{\mathrm{f}}^{\prime}$ and $D_{\mathrm{n}}^{\prime}$ distances are always measured from the perceived (terminal) positions of the head (Hypothesis 2 ). The geographic perceived motion ( $\left.d_{s}^{\prime}\right)$ of the stimulus in the B situations is determined by the tandem motion, here assumed to equal $d_{\mathrm{h}}^{\prime}$, and by $D_{\mathrm{f}}^{\prime}-D_{\mathrm{n}}^{\prime}$, which is influenced by the error in the perceived distance of the stimulus as shown in Situation $\mathrm{A}$. Whether or not a difference between $d_{\mathrm{b}}^{\prime}$ and $d_{h}$ occurred in any of the experiments of this study is not known. 